\title{
Sensitivity of Global Modeling Initiative chemistry and transport model simulations of radon-222 and lead-210 to input meteorological data
}

\author{
D. B. Considine ${ }^{1}$, D. J. Bergmann ${ }^{2}$, and H. Liu ${ }^{3}$ \\ ${ }^{1}$ NASA Langley Research Center, Hampton, Virginia, USA \\ ${ }^{2}$ Lawrence Livermore National Laboratory, Livermore, California, USA \\ ${ }^{3}$ National Institute of Aerospace, Hampton, Virginia, USA
}

Received: 19 May 2005 - Published in Atmos. Chem. Phys. Discuss.: 28 July 2005

Revised: 26 October 2005 - Accepted: 19 November 2005 - Published: 16 December 2005

\begin{abstract}
We have used the Global Modeling Initiative chemistry and transport model to simulate the radionuclides radon-222 and lead-210 using three different sets of input meteorological information: 1. Output from the Goddard Space Flight Center Global Modeling and Assimilation Office GEOS-STRAT assimilation; 2. Output from the Goddard Institute for Space Studies GISS II' general circulation model; and 3. Output from the National Center for Atmospheric Research MACCM3 general circulation model. We intercompare these simulations with observations to determine the variability resulting from the different meteorological data used to drive the model, and to assess the agreement of the simulations with observations at the surface and in the upper troposphere/lower stratosphere region. The observational datasets we use are primarily climatologies developed from multiple years of observations. In the upper troposphere/lower stratosphere region, climatological distributions of lead-210 were constructed from $\sim 25$ years of aircraft and balloon observations compiled into the US Environmental Measurements Laboratory RANDAB database. Taken as a whole, no simulation stands out as superior to the others. However, the simulation driven by the NCAR MACCM3 meteorological data compares better with lead-210 observations in the upper troposphere/lower stratosphere region. Comparisons of simulations made with and without convection show that the role played by convective transport and scavenging in the three simulations differs substantially. These differences may have implications for evaluation of the importance of very short-lived halogen-containing species on stratospheric halogen budgets.
\end{abstract}

Correspondence to: D. B. Considine

(david.b.considine@nasa.gov)

\section{Introduction}

Global modeling of the distributions of radionuclides in the troposphere and stratosphere is a classic problem in the study of atmospheric composition. Radionuclide simulations are interesting because the species are not chemically reactive, and have properties such as their sources, radioactive lifetime, or solubility which allow the identification and evaluation of controlling physical processes. As a result they have been used both to investigate atmospheric processes and to test representations of those processes in atmospheric models. This paper discusses simulations of two of these radionuclides, radon-222 $\left({ }^{222} \mathrm{Rn}\right)$ and lead-210 $\left({ }^{210} \mathrm{~Pb}\right)$, using a chemistry and transport model (CTM) developed by the Global Modeling Initiative (GMI).

Radon-222 is a short-lived and insoluble gas, with a radioactive half-life of 3.8 days. It is emitted primarily from non-frozen ground at a rate of about 1 atom cm $\mathrm{cm}^{-2} \mathrm{~s}^{-1}$ (Turekian et al., 1977), although there can be significant (factor of 2) differences in the emission rate depending on soil characteristics. Emission rates from frozen ground are significantly reduced, and the emission of ${ }^{222} \mathrm{Rn}$ from the oceans is negligible. The radionuclide has proved useful for investigating rapid transport processes such as convection (Mahowald et al., 1997; Stockwell et al., 1998), continental influence on remote ocean locations (Balkanski et al., 1992), the diurnal variability of the planetary mixed layer (Jacob and Prather, 1990), synoptic variability (Allen et al., 1996), and differences between on-line and off-line transport (Dentener et al., 1999). It has also been used in a major intercomparison of tropospheric transport models (Jacob et al., 1997).

Rn-222 decays to ${ }^{210} \mathrm{~Pb}$, which has a radioactive half-life of 22.3 years. Once formed it rapidly binds to atmospheric submicron aerosols (Sanak et al., 1981). It is therefore removed from the atmosphere in the same manner as aerosols,

(C) 2005 Author(s). This work is licensed under a Creative Commons License. 
Table 1. Characteristics of GMI model simulations.

\begin{tabular}{llllllll}
\hline Data Set & $\begin{array}{l}\text { Number } \\
\text { of levels }\end{array}$ & $\begin{array}{l}\text { Top } \\
\text { Pressure } \\
(\mathrm{hPa})\end{array}$ & $\begin{array}{l}\text { Vertical } \\
\text { Coordinate }\end{array}$ & $\begin{array}{l}\text { Interface } \\
\text { Pressure } \\
(\mathrm{hPa})\end{array}$ & $\begin{array}{l}\text { Bottom } \\
\text { layer } \\
\text { depth } \\
(\mathrm{hPa})\end{array}$ & $\begin{array}{l}\text { Update } \\
(\mathrm{m})\end{array}$ & $\begin{array}{l}\text { Period } \\
(\mathrm{h})\end{array}$ \\
\hline GISS II' & 23 & 0.002 & $\sigma-\mathrm{P}$ & 150 & 24.46 & $\sim 200$ & 3 \\
NCAR MACCM3 & 52 & 0.0047 & $\sigma-\mathrm{P}$ & 78.51 & 14.89 & $\sim 120$ & 3 \\
GMAO GEOS-STRAT & 46 & 0.1 & $\sigma$ & $\mathrm{NA}$ & 12.13 & $\sim 100$ & 6 \\
\hline
\end{tabular}

primarily through wet scavenging. Because its distribution is sensitive to wet scavenging, ${ }^{210} \mathrm{~Pb}$ has been used to test scavenging parameterizations in global models (Balkanski et al., 1993; Feichter et al., 1991; Guelle et al., 1998; Lee and Feichter, 1995; Liu et al., 2001). Its distribution is also sensitive to large scale transport and convection (Preiss et al., 1996).

The GMI is a NASA-funded, multi-institutional project, with a goal of improving assessments of anthropogenic perturbations to the Earth system. To achieve this goal the GMI is developing and utilizing atmospheric models which facilitate the testing of model sensitivities and uncertainties, and subjecting the models to extensive evaluation against observations of atmospheric composition. The GMI produced a CTM appropriate for stratospheric assessments (Rotman et al., 2001), which was used to evaluate the potential effects of stratospheric aircraft on the global stratosphere (Kinnison et al., 2001) and on the Antarctic lower stratosphere (Considine et al., 2000). An improved version of this model was used more recently in several sensitivity studies of the stratosphere and stratospheric response to anticipated decreases in stratospheric chlorine loading (Considine et al., 2004a; Douglass et al., 2004; Strahan and Douglass, 2004). A version of the GMI CTM has been developed recently which includes tropospheric physical and chemical processes and is thus capable of simulating the above-mentioned radionuclides throughout the troposphere and stratosphere (Considine et al., 2004b; Rodriguez et al., 2004).

The CTM uses meteorological data such as horizontal winds, convective mass fluxes, and precipitation fields which are not generated by the CTM itself, but instead are taken from the output of a general circulation model (GCM) or data assimilation system (DAS). One of the features of the GMI CTM is the ability to run the model with several sets of meteorological data. This capability enables evaluation of the sensitivity of radionuclide simulations to differences in the meteorological data sets alone. Such an approach has advantages compared to the more traditional approach of intercomparing simulations from several models, each utilizing a different source of meteorological data. This is because the number of factors which might produce differences in the simulations is reduced.
Our goal in this paper is to characterize the variability occurring in radionuclide simulations driven by three different meteorological data sets and to evaluate those simulations with a variety of observations. We seek to understand if the comparisons indicate a reasonable representation of the physical characteristics of the real atmosphere, and if it is possible to identify with the available observations a particular representation which is superior to the others, either in part or in whole. Section 2 describes the structure of the GMI three-dimensional (3-D) CTM. Section 3 presents the specifics of the radionuclide experiments we have conducted. Section 4 presents the results of our simulations and comparisons with observations. We summarize and present some conclusions in Sect. 5.

\section{Model description}

We used a version of the GMI model with the same basic structure as described in Rotman et al. (2001), but which also includes parameterizations of the important tropospheric physical processes, including convection, wet scavenging, dry deposition, and planetary boundary layer mixing. Winds, temperatures, and other meteorological quantities used in the model parameterizations described in this paper were taken from two different GCMs and one DAS. The two GCM data sets are from: 1. The Middle Atmosphere version of the National Center for Atmospheric Research (NCAR) Community Climate Model, version 3 (MACCM3) (Kiehl et al., 1998) and 2. The Goddard Institute for Space Studies version II' (GISS II') GCM (Koch and Rind, 1998). The assimilated data set is from the NASA Global Modeling and Assimilation Office (GMAO) GEOS-STRAT data assimilation system (Allen et al., 1996). Each of the data sets spans a single year. The GMAO data set represents the period from 1 March 1997 to 28 February 1998. The two GCM data sets do not correspond to any particular year, but are intended to be plausible realizations of the contemporary climatological state of the Earth's atmosphere.

In all three simulations the horizontal resolution is $4^{\circ}$ latitude by $5^{\circ}$ longitude. The characteristics of the model vertical coordinate were adopted from the different data sets, as 
shown in Table 1. The table shows that for the simulation driven by the GISS II' data set, the model was configured to have 23 levels extending from the surface to $0.002 \mathrm{hPa}$. The vertical coordinate was a hybrid configuration consisting of sigma (terrain-following) levels below an interface pressure of $150 \mathrm{hPa}$, smoothly transitioning to constant pressure levels above the interface. The depth of the bottom layer was the largest of the three data sets at $\sim 24 \mathrm{hPa}(\sim 200 \mathrm{~m})$, as the relatively smaller number of vertical levels would suggest. Meteorological information from the GISS II' data set was updated in the model every three hours. Table 1 provides similar information for the NCAR and GMAO data sets. Figure 1 compares the spacing and extent of the levels for each of the model simulations. Figure 1a shows their entire vertical domains, while Fig. 1b shows the vertical ranges up to $100 \mathrm{hPa}$, a pressure which typically lies near the tropopause in the tropics.

The model time step for each simulation was $1 \mathrm{~h}$. The model uses operator-splitting, meaning that the simulated radionuclide distributions are updated by a single time step after each module representing a physical or chemical process has been called and allowed to change the radionuclide concentrations in sequential order. The flux-form semiLagrangian advection scheme of Lin and Rood (1996) was used in each simulation. A "pressure fixer" was used to prevent any drift between the surface pressure imported from the meteorological data with a frequency of 3 or $6 \mathrm{~h}$ and the mass of the column above the surface, as described in Douglass et al. (2004).

The model parameterization for convective transport of trace species was adapted from the CONVTRAN routine contained in the NCAR CCM3 physics package (Kiehl et al., 1998). The same convective transport scheme was used with each meteorological data set rather than attempting to implement separate schemes for each data set. However, the convective transport calculated by the GMI model should be close to that of the parent GCMs due to its utilization of convective mass fluxes, entrainment and detrainment rates taken from the meteorological output of the parent GCMs. (The GMAO GEOS-STRAT DAS used the Relaxed ArakawaSchubert scheme of Moorthi and Suarez (1992) to simulate convection. Convection in the GISS II' GCM was parameterized as in DelGenio and Yao (1992). In the NCAR MACCM3 GCM, the Zhang and McFarlane (1995) scheme was used.)

The importance of scavenging in convective updrafts has long been recognized. Balkanski et al. (1993) was the first to couple scavenging with convective mass transport in a CTM. The process is included as part of the model convective transport scheme. The amount of tracer scavenged in a convective column of thickness $\Delta z(\mathrm{~m})$ depends on the convective loss frequency $L_{c}\left(\mathrm{~s}^{-1}\right)$ (i.e., the conversion rate of cloud water to precipitation), and an updraft velocity parameter, $v_{u}\left(\mathrm{~m} \mathrm{~s}^{-1}\right)$,
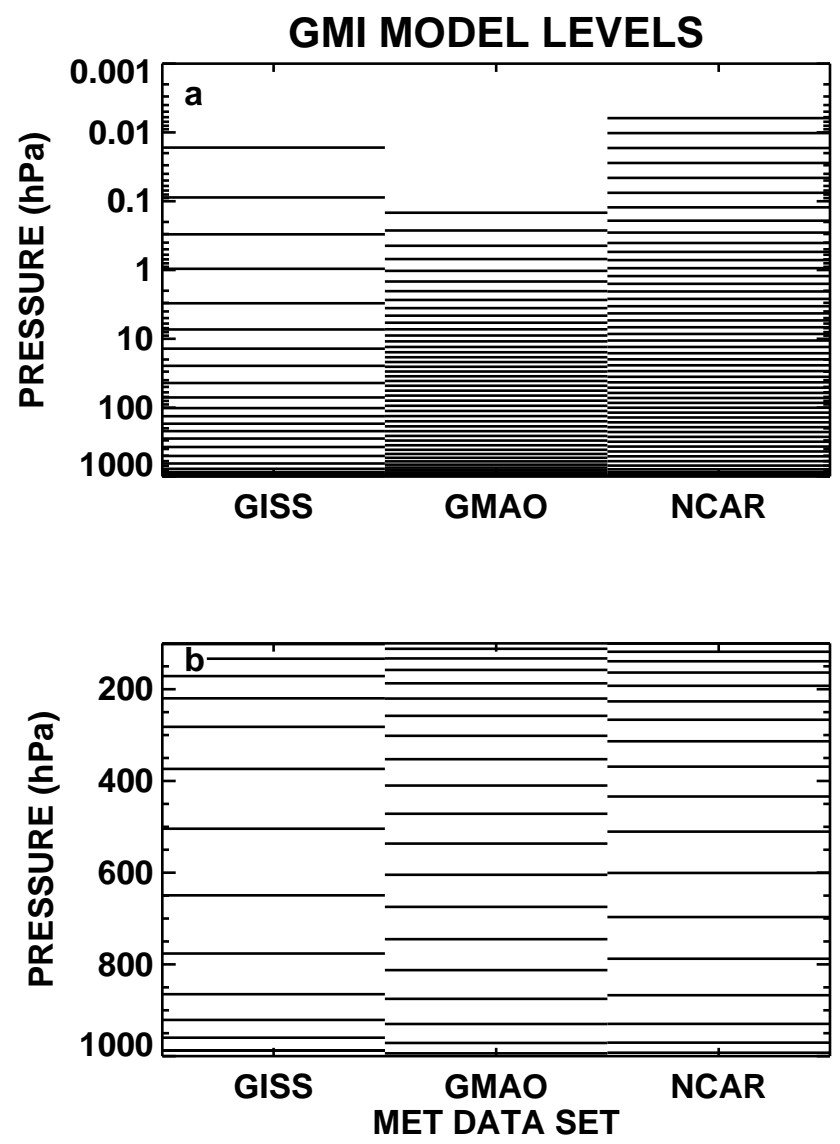

Fig. 1. Spacing of vertical levels in the three GMI simulations, assuming a surface pressure of $1000 \mathrm{hPa}$. (a) shows the model level midpoint values over the entire vertical ranges of the meteorological data. (b) shows the spacing up to $100 \mathrm{hPa}$.

with the scavenged fraction given by Liu et al. (2001):

$f_{s}=1-\exp \left(-L_{c} \Delta z / v_{u}\right)$.

For the simulations described in this paper, ${ }^{222} \mathrm{Rn}$ is taken to be insoluble and is not scavenged. For ${ }^{210} \mathrm{~Pb}$, the loss frequency was set to $0.005 \mathrm{~s}^{-1}$. The updraft velocity parameter was set to $10 \mathrm{~m} \mathrm{~s}^{-1}$ over land and $5 \mathrm{~m} \mathrm{~s}^{-1}$ elsewhere. For a $1 \mathrm{~km}$ deep convective column, these values result in $\sim 40 \%$ of the tracer scavenged from the grid box over land and $\sim 63 \%$ elsewhere.

The GMI model also applies the first-order scavenging scheme developed at Harvard University (Liu et al., 2001) to treat scavenging in large-scale stratiform and convective precipitation. In this scheme, rainout (in-cloud scavenging) follows Giorgi and Chameides (1986), while washout (below-cloud scavenging) follows Balkanski et al. (1993). One difference between the GMI and Harvard schemes is the assumed stratiform cloud condensed water content. This has been reduced in the GMI scheme from $1.5 \times 10^{-6}$ grams condensed water per $\mathrm{cm}^{3}$ cloud volume to $0.5 \times 10^{-6} \mathrm{~g} \mathrm{~cm}^{-3}$ 


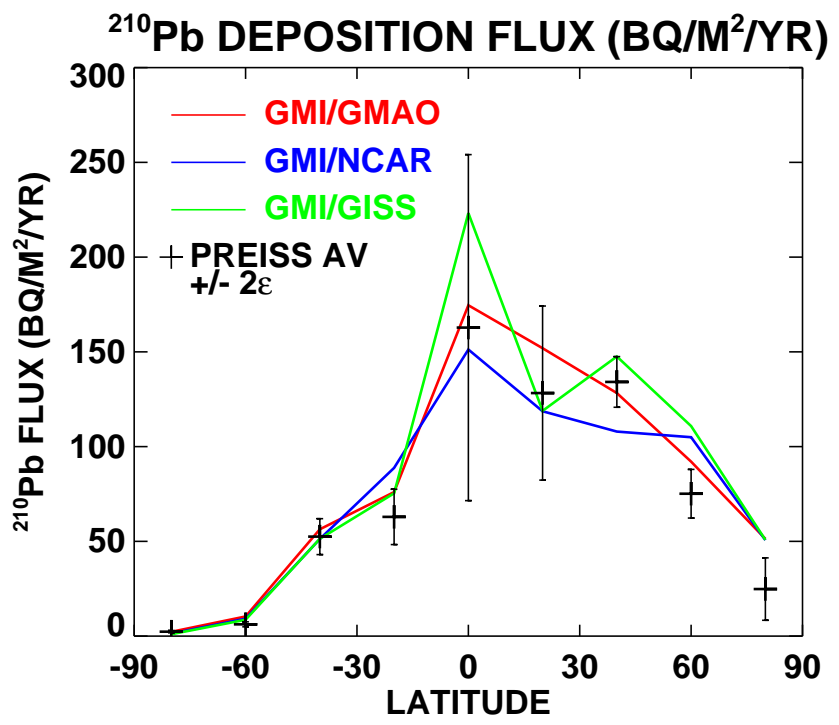

Fig. 2. Meridional distribution of annually averaged ${ }^{210} \mathrm{~Pb}$ deposition flux in the GMI model simulations compared to observations, in $\mathrm{Bq} \mathrm{m}^{-2} \mathrm{yr}^{-1}$. Observations were grouped into $20^{\circ}$ latitude bins and averaged. Error bars represent \pm 2 times the standard error of the average values. Model values were obtained by interpolating the gridded output to each site location, then averaging model output in same manner as observations.

to be consistent with measurements (Gayet et al., 2002; Nicholls and Leighton, 1986).

Dry deposition loss rates are calculated using the dry deposition algorithm described in Wang et al. (1998), which follows the methodology of Wesely et al. (1985). At each time step and for each surface grid box, this algorithm computes an aerodynamic resistance to deposition, which is dependent on meteorological conditions and surface type. A surface resistance is also calculated which depends on the meteorological conditions, the surface type, and a seasonal leaf area index (Wang et al., 1998). Surface resistance components for the deposition land types are from Wesely (1989), except for tropical forests (Jacob and Wofsy, 1990) and for tundra (Jacob et al., 1992). The module then employs a resistance in series approach to calculate a dry deposition velocity for the radon gas (very small) and the aerosol to which the ${ }^{210} \mathrm{~Pb}$ has attached.

Mixing within the planetary boundary layer (PBL) was done each $1 \mathrm{~h}$ time step and in each column. For the simulations using the MACCM3 and GMAO meteorological data sets, vertical diffusion coefficients $\left(K_{z z}\right)$ are supplied each 3 or $6 \mathrm{~h}$. These are then applied in an implicit scheme to solve for new mixing ratios within the entire column. This technique could not be applied for simulations using the GISS II' data due to the lack of PBL diffusion coefficients in our data set. In this case, grid boxes within the PBL were mixed with a relaxation time of $3 \mathrm{~h}$. The PBL height was obtained from the GISS meteorological data set and varies each $3 \mathrm{~h}$.

Gravitational settling was calculated as described in Se- infeld and Pandis (1998) (see their Eq. 8.42). We assumed an aerosol density of $1.77 \mathrm{~g} \mathrm{~cm}^{-3}$, an effective radius of 0.34 microns and a correction for swelling due to humidity from Gong et al. (1997). For small (sub micron size) aerosols the tropospheric velocity will be about $0.003 \mathrm{~cm} \mathrm{~s}^{-1}$ and could be ignored in the troposphere because the total settling during a characteristic 1 week lifetime can be as small as $20 \mathrm{~m}$. The reason for including gravitational settling of small aerosols is to accurately represent the upper troposphere and stratosphere. In those regions the atmospheric lifetime can be much longer than a week and the settling velocities increase non-linearly with height due to the lower densities of the stratosphere. Without a gravitational settling term there would be no loss term in the stratosphere other than stratosphere-to-troposphere gas transport and ${ }^{210} \mathrm{~Pb}$ would tend to accumulate there.

\section{Simulations}

Three simulations are intercompared in this paper. The primary difference between the simulations was the meteorological data used to drive the model (NCAR MACCM3, GMAO GEOS_STRAT, GISS II'). Each simulation was run for six years, with the meteorological data recycled for each year of the simulation. This was done to reach an approximately annually repeating steady state condition. The last year of output for each simulation was then used for analysis. In all of the GMI simulations, ${ }^{222} \mathrm{Rn}$ was introduced into the lowest model grid box over all non-frozen land surfaces at the rate of 1 atom $\mathrm{cm}^{-2} \mathrm{~s}^{-1}$. This is a standard assumption in model simulations, but it neglects the fact that there can be substantial local variations in ${ }^{222} \mathrm{Rn}$ emission rate (e.g., Lee et al., 2004). We also reduced the emission rate by $40 \%$ over land when the surface air temperature dropped below $273.15 \mathrm{~K}$ to account for the reduction in emission from freezing ground. Emission over oceans was set to 0.005 atom $\mathrm{cm}^{-2} \mathrm{~s}^{-1}$, and there was no emission over ice. The radioactive lifetime of ${ }^{222} \mathrm{Rn}$ was set to e-fold every 5.5 days (a 3.8 day half-life), and the species decayed to ${ }^{210} \mathrm{~Pb}$. In addition to radioactive decay, ${ }^{222} \mathrm{Rn}$ was also subject to loss by dry deposition. In the simulations, ${ }^{210} \mathrm{~Pb}$ was produced from the decay of ${ }^{222} \mathrm{Rn}$. No other source of ${ }^{210} \mathrm{~Pb}$ was considered. In the simulations it was treated as a soluble species and subjected to wet scavenging. Because ${ }^{210} \mathrm{~Pb}$ is attached to submicron aerosols in the atmosphere, the species was subjected to gravitational settling. The species was destroyed through dry deposition in addition to wet scavenging.

\section{Results}

\section{$4.1 \quad \mathrm{Rn}-222$}

After an atom of ${ }^{222} \mathrm{Rn}$ is emitted from the surface it either decays radioactively to ${ }^{210} \mathrm{~Pb}$, or is removed at the surface via 
dry deposition. The amount of ${ }^{222} \mathrm{Rn}$ converted to ${ }^{210} \mathrm{~Pb}$ is far larger than the amount lost via dry deposition. The ${ }^{222} \mathrm{Rn}$ which is converted to ${ }^{210} \mathrm{~Pb}$ is then lost from the atmosphere via dry and wet deposition of ${ }^{210} \mathrm{~Pb}$. Thus, a comparison of simulated and observed ${ }^{210} \mathrm{~Pb}$ deposition can be used to check ${ }^{222} \mathrm{Rn}$ emissions, at least in the global average. Transport and scavenging of ${ }^{210} \mathrm{~Pb}$ will influence the geographical distribution of ${ }^{210} \mathrm{~Pb}$ deposition but not the global average.

Figure 2 compares observed and simulated deposition fluxes of ${ }^{210} \mathrm{~Pb}$ as a function of latitude, in units of $\mathrm{Bq} \mathrm{m}^{-2} \mathrm{yr}^{-1}$. The observations are taken from a database of annually averaged deposition fluxes described in Preiss et al. (1996). The database compiles 392 estimates of annually averaged deposition fluxes from artificial collectors, snow, and soil measurements. The measurement sites span much of the globe, though the sampling pattern is not uniform. There are 94 sites in the database reporting artificial flux measurements, 102 sites reporting soil flux measurements, and 74 sites reporting ${ }^{210} \mathrm{~Pb}$ deposition in snow.

In Fig. 2, all sites falling within $20^{\circ}$ latitude bins centered at $-80^{\circ},-60^{\circ},-40^{\circ}, \ldots$ were averaged and the black crosses show these average values as a function of latitude. The error bars represent \pm two times the standard error of the averages. The colored red, blue, and green lines show the results from the GMI model driven with the GMAO GEOSSTRAT (red, labeled GMAO), NCAR MACCM3 (blue, labeled NCAR), and GISS II' (green, labeled GISS) meteorological data sets, respectively. The model averages were obtained by first interpolating model output to the site locations and then averaging the model results in the same manner as the observations. Figure 2 shows that the three model simulations agree very well with observations in the Southern Hemisphere high and middle latitudes. In the Northern Hemisphere high latitudes all three model simulations are somewhat higher than observed, suggesting either that annually averaged ${ }^{222} \mathrm{Rn}$ emissions in the Northern Hemisphere high latitudes are too large, or that horizontal transport between mid and high latitudes in the simulations is overly vigorous. In the Northern Hemisphere midlatitudes, the model simulations agree well with the observations though there is more variability amongst the simulations. The simulations show the largest variability in the tropics, which is also the location of the largest observed variability. The observed variability occurs because the tropical stations include sites of very high deposition in Western Africa (Barombi Mbo, Cameroon, and Lagos, Nigeria) as well as low values on the east coast of South America and Fanning Island in the Pacific. The variability in the simulations is primarily due to differences in simulated West African deposition. Globally, the simulated deposition flux agrees well with the observations, suggesting that the magnitude of the ${ }^{222} \mathrm{Rn}$ emissions is adequate. Note that globally integrated deposition will not be exactly the same in the three simulations because surface air temperature distributions differ in the three simulations, and were used in the ${ }^{222} \mathrm{Rn}$ emissions parameterization. How-

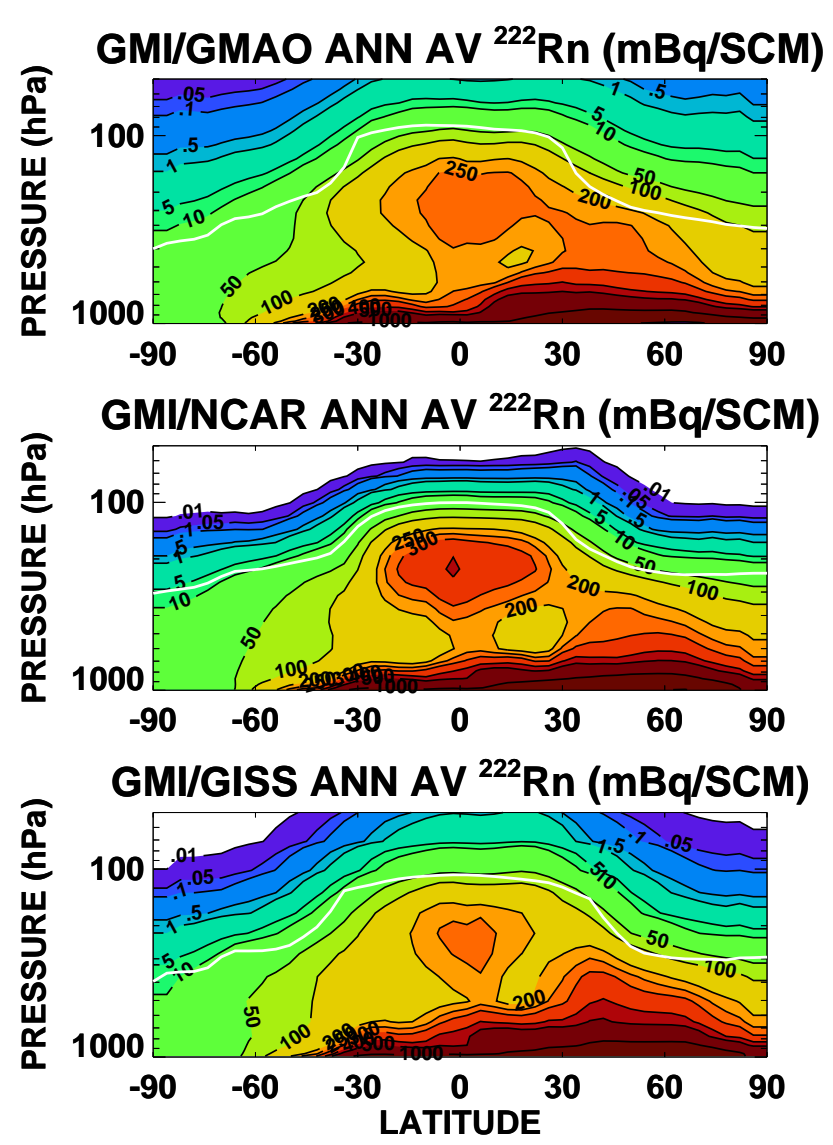

Fig. 3. Annually averaged zonal mean ${ }^{222} \mathrm{Rn}$ distributions in the three GMI simulations between 1000 and $50 \mathrm{hPa}$, in $\mathrm{mBq} \mathrm{SCM}^{-1}$. Top panel: GMI/GMAO simulation. Middle panel: GMI/NCAR simulation. Bottom panel: GMI/GISS simulation. Thick white line in each panel shows annually averaged location of the zonal mean thermal tropopause.

ever, globally integrated deposition in the three simulations differs by only $\sim 0.2 \%$.

After emission at the surface, ${ }^{222} \mathrm{Rn}$ is distributed globally by large-scale horizontal and vertical winds and convection. Figure 3 compares the annually averaged zonal mean distributions of ${ }^{222} \mathrm{Rn}$ produced in the three simulations, in units of millibequerel per standard cubic meter, a mixing ratio unit $\left(\mathrm{mBq} \mathrm{SCM}^{-1}\right)$. The heavy white line in each panel shows the location of the thermal tropopause. The figure shows that all three simulations exhibit relative maxima in the tropical upper troposphere. In all three cases the maxima appear to be caused by vigorous convective transport over subSaharan Africa and the Amazon basin. The higher tropical upper troposphere concentrations in the GMI/NCAR simulation (middle panel) suggest that its tropical convection transports ${ }^{222} \mathrm{Rn}$ into the tropical upper troposphere more effectively than the other two. (The effects of convective transport are discussed further in Sect. 4.3.) All three simulations have high ${ }^{222} \mathrm{Rn}$ concentrations near the ground in the Northern 


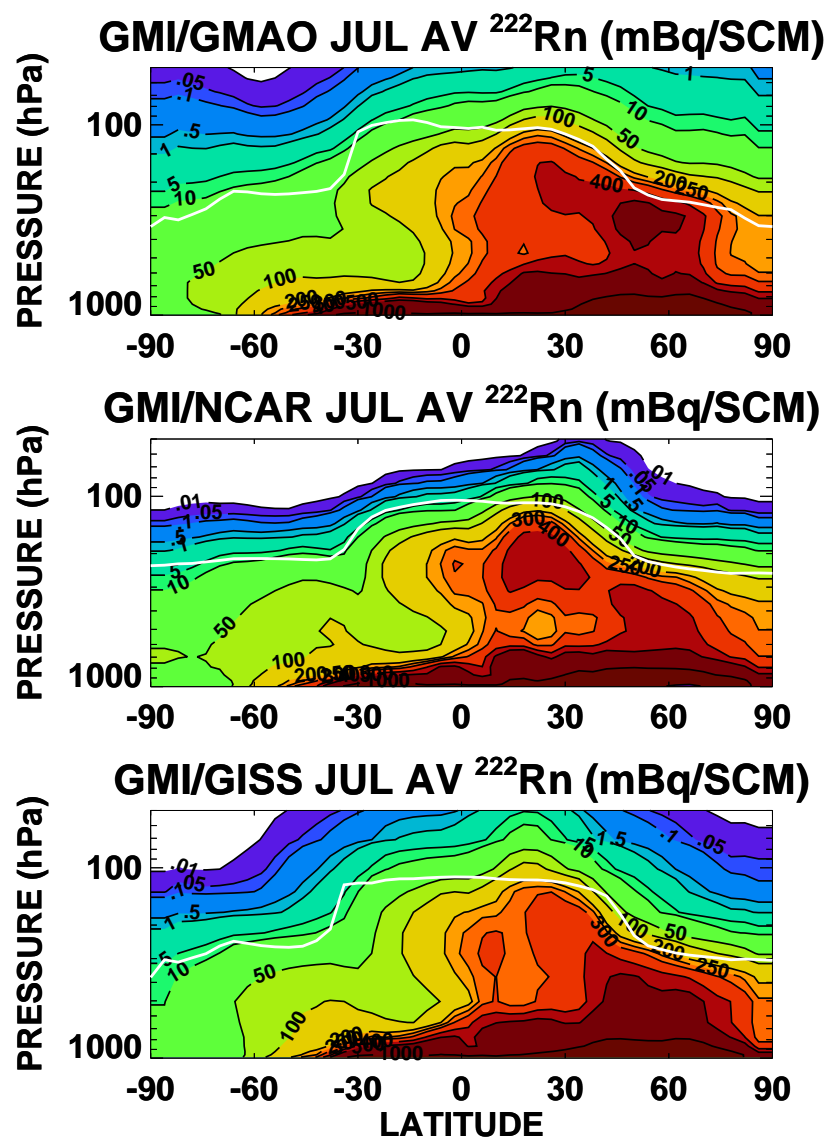

Fig. 4. Same as Fig. 3, except the plots represent July average values.

Hemisphere, reflecting the continental source of ${ }^{222} \mathrm{Rn}$ emissions. All three simulations also exhibit a local minimum of ${ }^{222} \mathrm{Rn}$ in the subtropical lower troposphere, an indication of the downward branch of the Hadley cell circulation.

Figure 3 also shows interesting differences between the simulations in the lower stratosphere. Specifically, the two GCM meteorological data sets (GMI/NCAR and GMI/GISS) produce ${ }^{222} \mathrm{Rn}$ distributions with much steeper lower stratospheric vertical gradients than the GMI/GMAO simulation, which is driven by the assimilated meteorological data. This difference reflects a well-known problem of high vertical diffusivity in simulations using assimilated meteorological data (Schoeberl et al., 2003). The GMI/GMAO simulation also has much larger ${ }^{222} \mathrm{Rn}$ concentrations just above the tropopause than the other two simulations, suggesting larger troposphere-to-stratosphere exchange in this simulation.

The importance of convective transport at a location varies with season. Figure 4 shows zonal mean ${ }^{222} \mathrm{Rn}$ distributions from the three simulations for July. The tropical upper tropospheric maxima are diminished in July relative to January, and there are large values in the midlatitude upper troposphere. In the GMI/GMAO simulation the midlatitude upper tropospheric values seen in the figure are located over north-

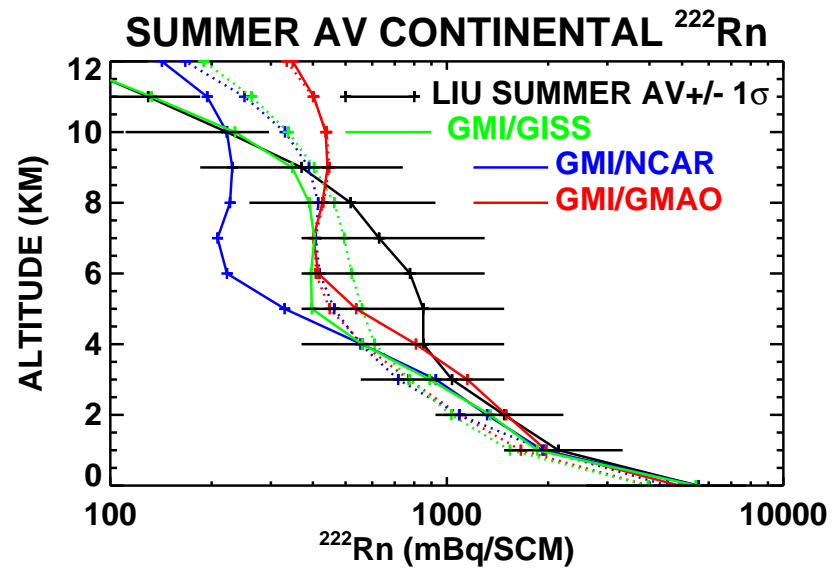

Fig. 5. Comparison of GMI model simulated vertical ${ }^{222} \mathrm{Rn}$ profiles with Liu et al. (1984) climatological summertime continental ${ }^{222} \mathrm{Rn}$ profile. The Liu et al. (1984) profile is shown with 1-sigma error bars. Model profiles were made by sampling model at the locations of the profiles used to produce the observed climatological profile, interpolating model output to a $1-\mathrm{km}$ vertical grid, and averaging. Dotted lines show area-weighted Northern Hemisphere midlatitude continental profiles to indicate representativeness of the profiles sampled according to the "Liu" climatology.

eastern Asia and eastern North America. In the GMI/NCAR simulation, the contribution from eastern North America is diminished and there are larger concentrations located over northern India extending eastward into western China. Upper tropospheric maxima in the GMI/GISS simulation are also in this location.

The ${ }^{222} \mathrm{Rn}$ distributions shown in Figs. 3 and 4 are qualitatively consistent with expectations in all three simulations (Jacob et al., 1997), but there are quantitative differences. Unfortunately the number of atmospheric measurements of ${ }^{222} \mathrm{Rn}$ with which the model simulations can be compared is small due to the short lifetime of ${ }^{222} \mathrm{Rn}$ and the need for in situ sampling. Liu et al. (1984) published one of the most extensive compilations of ${ }^{222} \mathrm{Rn}$ profile measurements made at northern hemisphere continental locations. Figure $5 \mathrm{com}$ pares model profiles with the summer climatological profile from the Liu et al. (1984) study. The Liu et al. (1984) profile combines 23 summertime profiles taken over the United States and eastern Ukraine. The model profiles were obtained by calculating the three-dimensional altitude grids corresponding to the three-dimensional grids of ${ }^{222} \mathrm{Rn}$ concentrations, interpolating each to a $1-\mathrm{km}$ resolution altitude coordinate, sampling the model at the locations of the observed profiles, and averaging. Also shown in the figure to indicate the representativeness of the Liu et al. (1984) profiles are dotted lines showing area-weighted Northern Hemisphere $\left(30^{\circ}-60^{\circ}\right.$ latitude) summer continental average vertical profiles.

The Liu et al. (1984) summer climatology (black line with error bars) shows surface concentrations of $\sim 5000$ 
$6000 \mathrm{mBq} \mathrm{SCM}{ }^{-1}$, and an average decrease of about $1000 \mathrm{mBq} \mathrm{SCM}^{-1}$ up to about $4 \mathrm{~km}$. Between $4 \mathrm{~km}$ and $8 \mathrm{~km}$ the rate of decrease slows, a profile feature which is interpreted as a consequence of convective transport. All three simulations agree well with the observed profiles up to $\sim 4 \mathrm{~km}$. Above $4 \mathrm{~km}$ the model profiles continue to decrease for an additional $1-2 \mathrm{~km}$ before their rates of decrease slow down. As a result the simulated profiles have lower than observed ${ }^{222} \mathrm{Rn}$ concentrations in the $4-8 \mathrm{~km}$ region and higher than observed values above $\sim 9-10 \mathrm{~km}$, though the simulation driven by the GISS II' meteorology agrees best. A possible explanation for this behavior is that convective mass detrainment in all three simulations occurs at too high an altitude. Note that the very low mid-tropospheric values seen in the NCAR MACCM3 profile obtained by sampling the model at observation locations is not representative of the summertime continental average profile (dotted blue line in Fig. 5). The summertime continental average profile has factor of two higher midtropospheric concentrations, and agrees better with the observations and the other model simulations.

Another set of potentially useful ${ }^{222} \mathrm{Rn}$ profile measurements was published by Kritz et al. (1998). The balloon profiles were taken over Moffett Field, California (37.4 N, $122.0^{\circ} \mathrm{W}$ ) during spring and summer of 1994 . Figure $6 \mathrm{com}-$ pares the average of the 7 profiles made during June with June average profiles from the 3 simulations. (Note that none of the GMI simulations uses meteorological data corresponding to June 1994; these comparisons must interpreted accordingly.) The figure shows the observed average profile with error bars representing \pm 2 times the standard error of the measurements (black line), model profiles sampled at the measurement locations (solid red, blue, and green lines), and model profiles sampled $5^{\circ}$ longitude west of the measurement locations (dotted red, blue, and green lines). Near the surface, the simulated values consistently exceed observations by a factor of $2-3$. However, the dotted profiles indicate that longitudinal gradients near the surface are very large due to the fact that Moffett Field lies near the Pacific Ocean and is affected by onshore flow. The $5^{\circ}$ longitudinal resolution of the model is too coarse to represent this gradient very well. Above $4 \mathrm{~km}$ the horizontal gradients are not as steep. Simulated ${ }^{222} \mathrm{Rn}$ concentrations in the $4-10 \mathrm{~km}$ region are up to $50 \%$ low. The spread between the three simulations suggests that the model/measurement discrepancy at these altitudes could be due to meteorological variability. However, simulations using meteorological data valid for 1994, which were presented in the recent study of Gupta et al. (2004), also exhibit low ${ }^{222} \mathrm{Rn}$ concentrations compared to the Moffett Field observations. Vertical gradients agree well with the observations. Note that at these altitudes and longitudes, the majority of the ${ }^{222} \mathrm{Rn}$ is from Australia and Asia (Stockwell et al., 1998). The comparison therefore tests emission rates and vertical transport over those continents, as well as transport pathways to North America, rather than the simulation of local convective processes. Low simulated Asian emis-

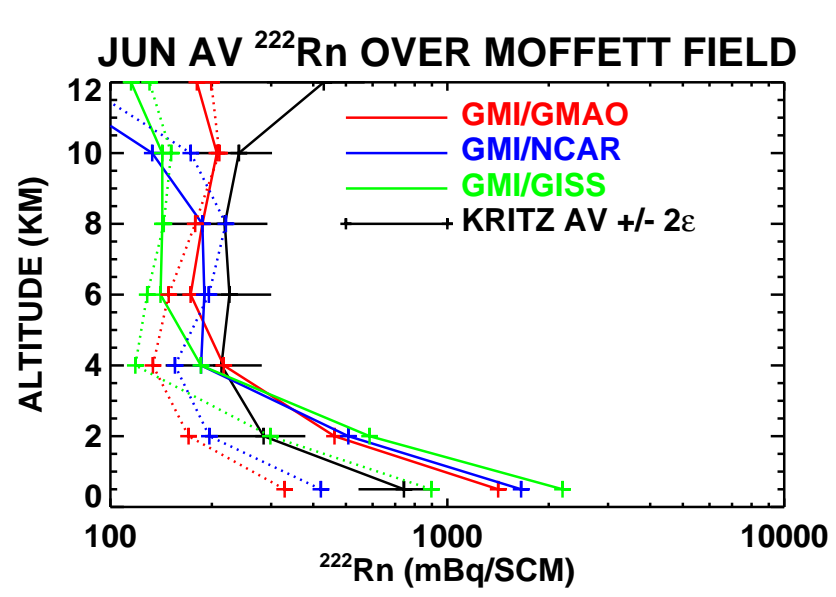

Fig. 6. Comparison of GMI model simulations of vertical ${ }^{222} \mathrm{Rn}$ profiles with profiles constructed from observations taken over Moffett Field, CA in June (Kritz et al., 1998). Black solid line shows June average profile from observations. Error bars represent \pm 2 times the standard error of the averages. Solid colored lines represent model profiles over Moffett field. Dotted colored lines are profiles from $5^{\circ}$ longitude west of the Moffett field profiles to indicate longitudinal gradients in ${ }^{222} \mathrm{Rn}$.

sions might therefore explain some of the model/measurment discrepancy in the $4-10 \mathrm{~km}$ region over Moffett Field. The possibility of high ${ }^{222} \mathrm{Rn}$ emissions over Asia is discussed in the recent paper of Lee et al. (2004).

Together, Figs. 5 and 6 indicate that Northern Hemisphere summertime continental vertical transport in the 3 simulations is reasonable, but convective outflow may be located at higher altitudes than in the real atmosphere.

\section{$4.2 \mathrm{~Pb}-210$}

The decay of ${ }^{222} \mathrm{Rn}$ results in formation of ${ }^{210} \mathrm{~Pb}$, so the atmospheric distribution of ${ }^{210} \mathrm{~Pb}$ depends on both the spatial and temporal variation of ${ }^{222} \mathrm{Rn}$. The loss of ${ }^{210} \mathrm{~Pb}$ from the atmosphere is governed primarily by wet scavenging, in both large-scale systems and convective updrafts. The fact that both the source and sink terms for ${ }^{210} \mathrm{~Pb}$ are spatially distributed and variable makes it more difficult to understand the processes governing the atmospheric distribution of ${ }^{210} \mathrm{~Pb}$.

Figure 7 compares the annually averaged zonal mean distributions of ${ }^{210} \mathrm{~Pb}$ for the GMI/GMAO, GMI/NCAR, and GMI/GISS simulations in the top, middle, and bottom panels, respectively. The three distributions show a number of qualitative similarities. Concentrations of ${ }^{210} \mathrm{~Pb}$ are high near the surface in the Northern Hemisphere tropics and midlatitudes, and very low near the surface in the Southern Hemisphere south of $\sim-45^{\circ}$. In the GMI/NCAR simulation, the high Northern Hemisphere values do not extend all the way to the pole, but decrease north of $\sim 75^{\circ}$. A band of elevated ${ }^{210} \mathrm{~Pb}$ occurs at or just above the tropical tropopause in all three simulations and extends into the lower stratosphere at mid to 


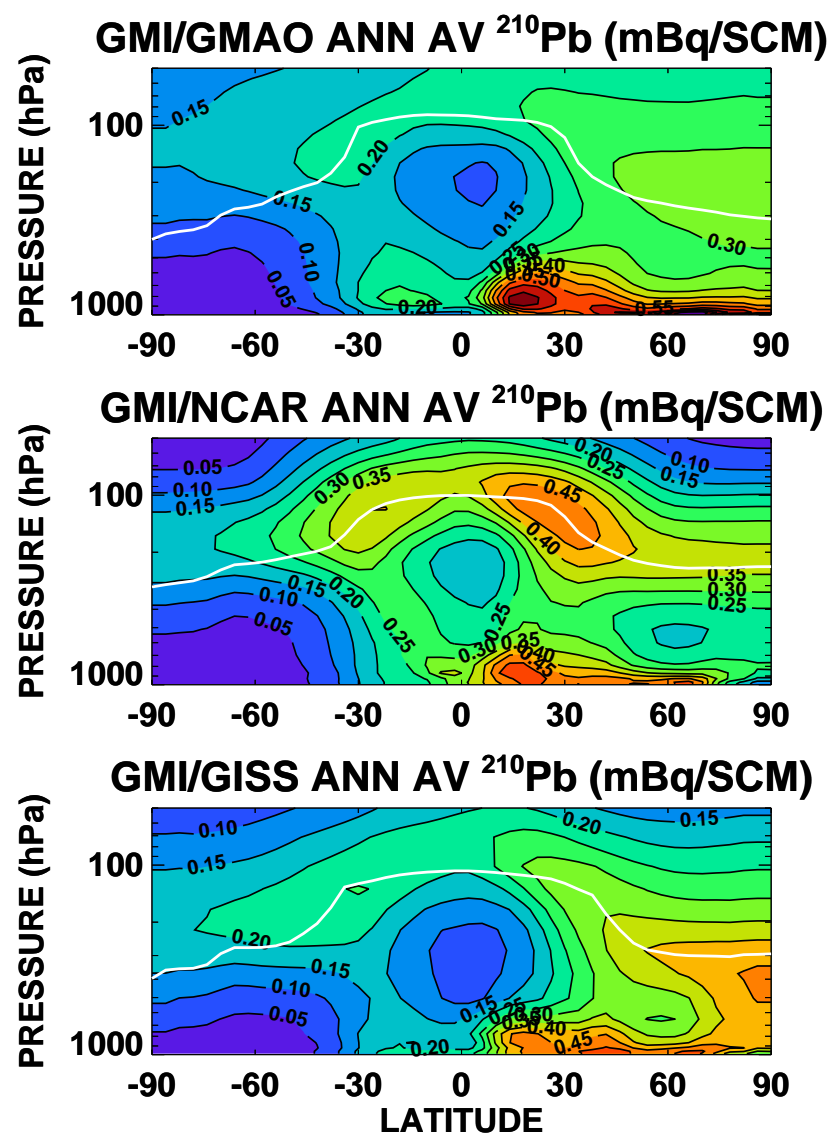

Fig. 7. Annually averaged zonal mean distributions of ${ }^{210} \mathrm{~Pb}$ in the GMI/GMAO simulation (top panel), GMI/NCAR simulation (middle panel), and GMI/GISS simulation (bottom panel) $(\mathrm{mBq}$ $\left.\mathrm{SCM}^{-1}\right)$. Thick white line shows location of annually averaged zonal mean thermal tropopause.

high latitudes in both hemispheres. This band is most pronounced in the GMI/NCAR simulation and least obvious in the GMI/GISS simulation. There is a local minimum in the ${ }^{210} \mathrm{~Pb}$ concentration in the tropical upper troposphere of all three simulations. The minimum is largest in the GMI/GISS simulation. In the Northern Hemisphere mid troposphere, the simulations also exhibit local minima though this feature is weak in the GMI/GISS simulation.

The characteristics of the ${ }^{210} \mathrm{~Pb}$ distributions which are shown in Fig. 7 result from the properties of the source, transport, and loss processes governing the constituent. The low surface concentrations in the Southern Hemisphere and elevated concentrations in the Northern Hemisphere near the surface reflect the distribution of unfrozen land over the Earth's surface, which governs ${ }^{222} \mathrm{Rn}$ and hence ${ }^{210} \mathrm{~Pb}$ production. The elevated band of ${ }^{210} \mathrm{~Pb}$ near the tropopause is due to the combined effects of resolved-scale vertical transport of both ${ }^{222} \mathrm{Rn}$ and ${ }^{210} \mathrm{~Pb}$ and convective transport of ${ }^{222} \mathrm{Rn}$. (Since ${ }^{210} \mathrm{~Pb}$ is mostly scavenged from convective plumes, concentrations of ${ }^{210} \mathrm{~Pb}$ in air moved by convection

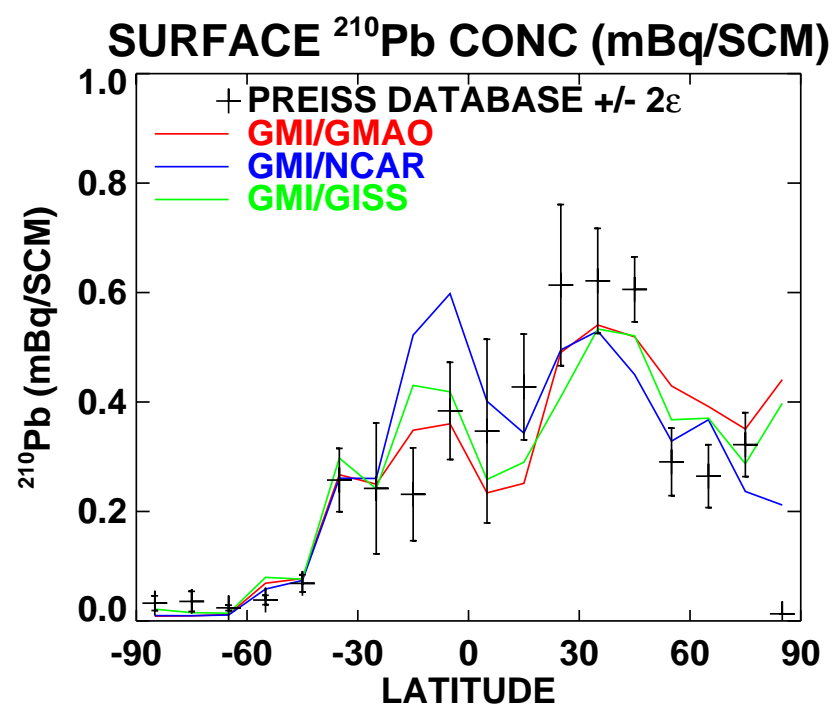

Fig. 8. Comparison of observed and simulated meridional distribution of annually averaged surface ${ }^{210} \mathrm{~Pb}$ concentrations. The observed distribution is calculated by averaging observations from the Preiss et al. (1996) database into $10^{\circ}$ latitude bins. Error bars represent \pm 2 times the standard error of the averages. Simulated distributions were obtained by sampling model output at observation locations and then treating model output in same manner as the observations.

from the surface to the mid and upper troposphere are smaller than upper tropospheric concentrations of ${ }^{210} \mathrm{~Pb}$ ).

The three simulations produce predictions for the distribution of ${ }^{210} \mathrm{~Pb}$ near the surface and higher in the atmosphere, which can be evaluated by comparison with observations. Figure 8 compares the meridional distribution of annuallyaveraged surface ${ }^{210} \mathrm{~Pb}$ concentrations from the three GMI simulations with observations. The observations are taken from the database of annually averaged ${ }^{210} \mathrm{~Pb}$ concentrations in surface air presented in Preiss et al. (1996). This database is an updated version of Lambert et al. (1982). The database compiles 225 separate measurements of annually-averaged ${ }^{210} \mathrm{~Pb}$ concentrations in surface air at 147 sites distributed around the globe. The measurement locations are concentrated in North and South America, the Arctic and Antarctic, Europe, India, Japan, and Australia. Few measurements are available from Africa or Asia. In Fig. 8, measurements from locations falling within $10^{\circ}$ latitude bands centered at $-85^{\circ}$, $-75^{\circ}, \ldots, 85^{\circ}$ were averaged together and plotted at bin centers. Error bars show \pm two times the standard error of the averages. Output from each of the model simulations was treated similarly to the observations; Annual average distributions of surface ${ }^{210} \mathrm{~Pb}$ were sampled at the measurement locations and then averaged.

Figure 8 shows that the model simulations capture the basic features of the meridional distribution of surface ${ }^{210} \mathrm{~Pb}$. Relatively low concentrations of ${ }^{210} \mathrm{~Pb}$ occur south of $-40^{\circ}$ 
Table 2. Simulated vs. observed average surface ${ }^{210} \mathrm{~Pb}$ concentrations ( $\left.\mathrm{mBq} \mathrm{SCM}{ }^{-1}\right)$. Standard error is given in parenthesis.

\begin{tabular}{lllll}
\hline Region (\# sites) & Preiss & GMI/GMAO & GMI/NCAR & GMI/GISS \\
\hline Arctic (15) & $0.29(0.08)$ & $0.35(0.10)$ & $0.24(0.06)$ & $0.29(0.08)$ \\
N. America (51) & $0.57(0.08)$ & $0.54(0.08)$ & $0.52(0.07)$ & $0.52(0.08)$ \\
S. America (30) & $0.25(0.05)$ & $0.32(0.06)$ & $0.41(0.09)$ & $0.37(0.08)$ \\
Europe (37) & $0.42(0.08)$ & $0.41(0.07)$ & $0.30(0.05)$ & $0.41(0.07)$ \\
India (24) & $0.76(0.16)$ & $0.64(0.14)$ & $0.66(0.14)$ & $0.58(0.13)$ \\
Japan (6) & $0.51(0.22)$ & $0.41(0.17)$ & $0.30(0.13)$ & $0.32(0.13)$ \\
Australia (10) & $0.18(0.06)$ & $0.17(0.06)$ & $0.17(0.06)$ & $0.15(0.06)$ \\
Antarctica (17) & $0.03(0.01)$ & $0.01(0.003)$ & $0.01(0.003)$ & $0.02(0.004)$ \\
N. Pacific (11) & $0.24(0.08)$ & $0.09(0.03)$ & $0.13(0.04)$ & $0.11(0.04)$ \\
\hline
\end{tabular}

in all three simulations. Southern Hemisphere midlatitude concentrations are generally lower than Northern Hemisphere midlatitude concentrations. Northern Hemisphere high latitude concentrations are much larger than in the Southern Hemisphere. The model simulations also show some similar discrepancies from the observations. Simulated concentrations of ${ }^{210} \mathrm{~Pb}$ in the Southern Hemisphere south of $-70^{\circ}$ are substantially lower than observations in all three simulations. All of the model simulations also underestimate ${ }^{210} \mathrm{~Pb}$ in the Northern Hemisphere midlatitudes by $\sim 15-$ $20 \%$. At high latitudes in the Northern Hemisphere the simulations tend to overestimate ${ }^{210} \mathrm{~Pb}$ but the variation between the models is relatively large, with the GMI/GMAO simulation in worst agreement and GMI/NCAR in best agreement. The largest variability between the simulations occurs in the $-10^{\circ}-0^{\circ}$ latitude band. The disagreement is due to the fact that the measurements in this band consist of 4 different annual average values made at Guayaquil, Ecuador. Since each of the model simulations use a single year of meteorological data they do not account for interannual variability. There is also no spatial averaging due to the fact that all of the measurements were made at Guayaquil. Thus, the large discrepancy between the model simulations only indicates a large variability in predicted surface air concentrations at Guayaquil. Zonal mean values in this band are in better agreement.

Table 2 compares regional averages of annually averaged surface ${ }^{210} \mathrm{~Pb}$ concentrations made using the measurements from the Preiss database with regional averages from the three GMI simulations. The model output was sampled at the site locations contained in the database. The table lists the average surface concentration in millibequerel per standard cubic meter along with the standard error in parentheses. Following each region name the table provides the number of measurements included in the average. In the Arctic the simulations agree with the Preiss et al. (1996) regional averages within standard error. In North America and Australia the simulations are consistently low but still within the database error limits. In South America all of the simu- lations exceed the Preiss et al. (1996) database average by more than the standard error, with the largest discrepancy in the GMI/NCAR simulation. In Europe the GMI/NCAR simulation is less than the observed regional average by more than the standard error, but the other two simulations agree well. In India, the GMI/GISS simulation is low. In Japan all three simulations are low, but within the fairly large observed standard error. Simulated Antarctic concentrations are consistently low, as shown in Fig. 8. The North Pacific average includes 11 island measurements and all the model simulations are low. Overall, no simulation demonstrates significantly better agreement with observations than the others. Table 2 reinforces the basic conclusions of low biases in surface concentrations of the Northern Hemisphere midlatitudes and Antarctica.

One possible explanation for the low bias in Northern Hemisphere midlatitude surface ${ }^{210} \mathrm{~Pb}$ is too little ${ }^{222} \mathrm{Rn}$ emission. However, the ${ }^{210} \mathrm{~Pb}$ deposition flux in the NH midlatitudes shown in Fig. 2 suggests that only the GMI/NCAR simulation may have this problem. Another more likely possibility is overly vigorous wet scavenging. We have found midlatitude surface concentrations of ${ }^{210} \mathrm{~Pb}$ to be quite sensitive to the condensed water content of stratiform clouds, assumed here to be $0.5 \times 10^{-6} \mathrm{~g} \mathrm{~cm}^{-3}$. This value was used by Georgi and Chameides (1986), and is consistent with past and recent observational estimates (Gayet et al., 2002; Nicholls and Leighton, 1986). Several previous studies have used higher values (Brost et al., 1991; Liu et al., 2001; Rehfeld and Heimann, 1995). A higher value would decrease scavenging and produce higher midlatitude surface ${ }^{210} \mathrm{~Pb}$ concentrations in better agreement with observations.

\subsubsection{RANDAB database}

Previous studies of atmospheric radionuclide distributions have typically relied on information from just a small number of balloon or aircraft measurements to evaluate simulated radionuclide concentrations above the Earth's surface. This was not due to a lack of measurements, but primarily because 

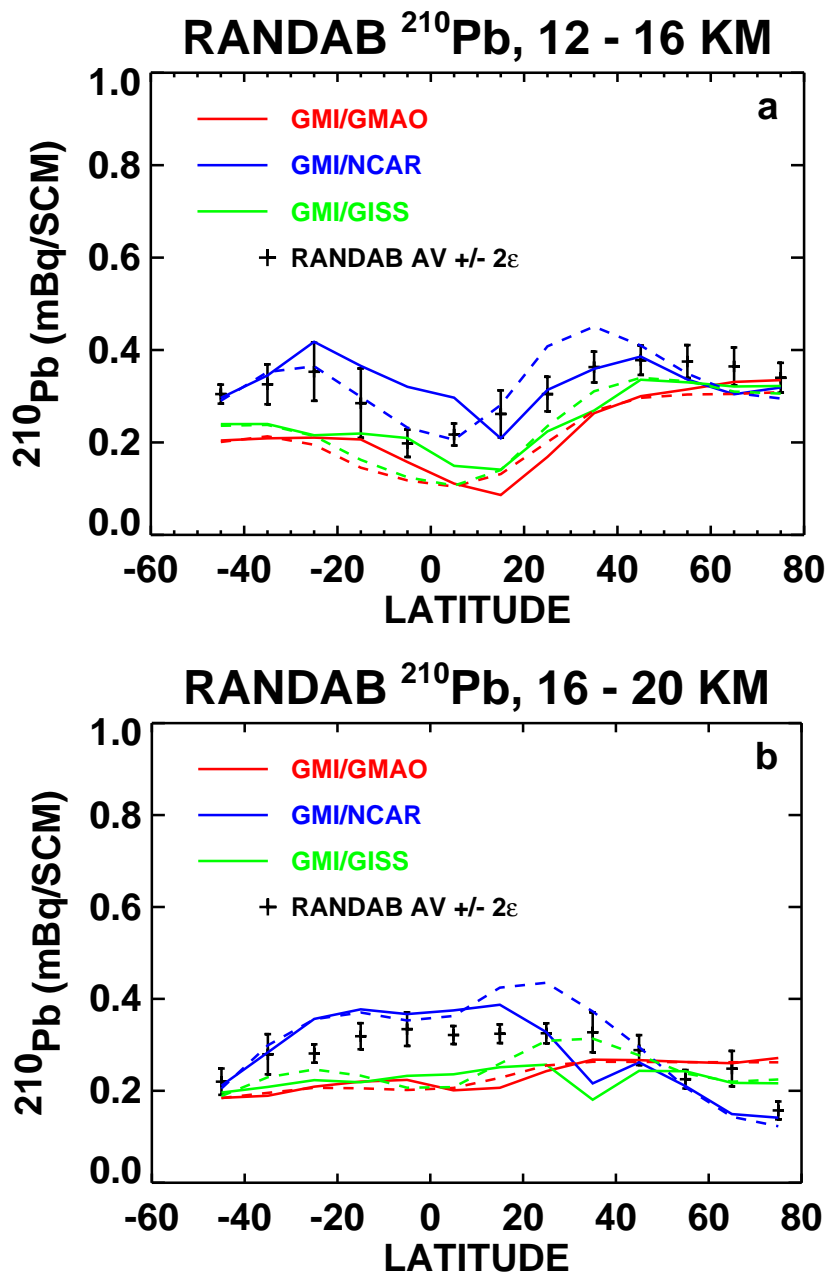

Fig. 9. Comparison of observed and simulated meridional distributions of ${ }^{210} \mathrm{~Pb}$ in the: (a) $12-16 \mathrm{~km}$ region, and (b) $16-20 \mathrm{~km}$ region. Observed distributions are calculated by averaging data from the US Environmental Measurement Laboratory RANDAB database into $10^{\circ}$ bins centered at $-45^{\circ},-35^{\circ}, \ldots, 75^{\circ}$. Error bars represent \pm 2 times the standard error of the averages. Simulated distributions are obtained by sampling model at observation locations and treating the sampled output in the same manner as the observations. Dashed lines are annually averaged zonal means in the $12-16 \mathrm{~km}$ and $16-20 \mathrm{~km}$ regions, plotted to indicate the representativeness of the observed and modeled distributions.

of the difficulty of obtaining the records. Between the late 1950s and the early 1980s, the Department of Energy (DOE) Environmental Measurements Laboratory (EML), which is now part of the Department of Homeland Security (DHS), collected tropospheric and stratospheric aircraft and balloon measurements of numerous radionuclides as part of the DOE High Altitude Sampling Program (HASP). HASP included the Ashcan project, which collected balloon samples at altitudes of 20-27 km from 1956 to 1983, the Stardust project, which used several types of instrumented air- craft to collect samples at altitudes of 6-19 km from 19611967, and the Airstream project, which basically was a continuation of Project Stardust through 1983. (An overview of the HASP program as well as web-based access to the Airstream, Stardust, and Ashcan data archives, is available at: http://www.eml.doe.gov/databases/hasp/). The data from these aircraft and balloon flights was also compiled into a database in 1997 by R. Leifer and N. Chan of the DOE (now DHS) EML, which was named RAdioNuclide DAtaBase (RANDAB). This database is currently available on the internet at the Oak Ridge National Laboratory's Carbon Dioxide Information Analysis Center (CDIAC), as database DB1019 (http://cdiac.esd.ornl.gov/ndps/db1019.html).

The RANDAB database contains information from 13240 samples, 7696 associated with the Stardust project, 3216 with the Airstream project, and 2329 from Ashcan. Of these, there are 3080 measurements of atmospheric ${ }^{210} \mathrm{~Pb}$ concentrations: 334 from Ashcan, 759 from Stardust, and the balance from Airstream. The measurements are fairly evenly distributed throughout the year. The smallest number of measurements is available for December (126) and the largest number is for July (454). Measurements are also fairly evenly distributed between 1957 and 1981 . The largest number is from 1973 (248).

All of the measurements were made in the Western Hemisphere. Typically measurements were made along a path leading north from about $50^{\circ} \mathrm{S}$ following the west coast of South America, crossing Panama into the Gulf of Mexico, turning northwest over the United States and west coast of Canada toward Anchorage, Alaska $\left(\sim 60^{\circ} \mathrm{N}, 150^{\circ} \mathrm{W}\right)$, and then northward at $\sim 150^{\circ} \mathrm{W}$ to as high as $75^{\circ} \mathrm{N}$. On a typical Stardust or Airstream flight, up to 12 air samples would be made. Each sample was collected for $\sim 45 \min \left(3^{\circ}-4^{\circ}\right.$ of latitude at typical flight speeds) in a flow-through system with an approximate inlet diameter of 24 inches on Institute of Paper Chemsitry (IPC) No. 1478 filter paper having a diameter of $\sim 16$ inches. Radionuclide activity was subsequently counted and combined with an estimate of sampling volume to produce the final measurement (sampling volume was not measured). The largest source of error in this system is likely to be the sampling volume estimate, followed by the filter paper collection efficiency (typically between 90 $100 \%$ ) (R. Leifer, personal communication, 1999). Of the $3080{ }^{210} \mathrm{~Pb}$ measurements we use in this paper, 737 are accompanied by an error estimate. These estimates can range from $<5 \%$ to $>100 \%$. We have chosen to use all measurements not flagged as questionable, regardless of error estimate.

Ashcan measurements were made from balloon flights launched from several locations distributed along the path described above. The measurements were made by forcing air through filter paper with a velocity sufficient to achieve a sampling efficiency of $>90 \%$. Most of the measurements were made between the years of 1965-1967 and 1972-1980. 


\subsubsection{Comparisons to RANDAB}

To compare the three radionuclide simulations with the ${ }^{210} \mathrm{~Pb}$ data contained in the RANDAB database, we first sampled the model distributions at the months, longitudes, latitudes, and altitudes of the ${ }^{210} \mathrm{~Pb}$ observations. This allowed us to treat the four data sets in an equivalent manner in subsequent analyses. Figure 9a compares the meridional distribution of ${ }^{210} \mathrm{~Pb}$ measurements made in the 12 to $16 \mathrm{~km}$ altitude range with the three GMI simulations. Figure $9 \mathrm{~b}$ shows the same comparison, but for observations in the 16 to $20 \mathrm{~km}$ range. The 12 to $16 \mathrm{~km}$ range, which corresponds approximately to the region between $200-100 \mathrm{hPa}$, lies within the upper troposphere in the tropics and the lower stratosphere at mid to high latitudes. The RANDAB observations in Fig. 9a lying between these two altitudes were collected into $10^{\circ}$ latitude bins centered at $-45^{\circ},-35^{\circ}, \ldots, 65^{\circ}$ and averaged. Figure 9 a shows the bin averages as a function of latitude, with error bars indicating \pm two times the standard error of the binned data points. Bin averages for the three GMI simulations are also shown as the solid red (GMAO), blue (NCAR) and green (GISS) lines. Also plotted on the figure as dashed lines are zonal means from the simulations for the $12-16 \mathrm{~km}$ region, to show the global representativeness of the averages constructed from sampling the simulations at the observation locations.

The observations in Fig. 9a indicate comparatively low tropical upper tropospheric values of $\sim 0.2 \mathrm{mBq} \mathrm{SCM}^{-1}$, with subtropical/midlatitude maxima $\sim 75 \%$ larger than the tropical minimum bordering the tropics in both hemispheres. The distribution is fairly symmetric about the equator, with the difference between the values of the observed maxima in the two hemispheres being smaller than the error limits. The GMI/NCAR simulation agrees reasonably well with the observations in the Northern Hemisphere and at the two most southern latitudes. In the range $30^{\circ} \mathrm{S}-10^{\circ} \mathrm{N}$ (i.e., the Southern Hemisphere subtropics and tropics), ${ }^{210} \mathrm{~Pb}$ concentrations in the GMI/NCAR simulation are somewhat higher than observed. The GMI/GMAO and GMI/GISS distributions are similar to each other, both showing a tropical minimum, with larger values in the midlatitudes. Both also show a stronger interhemispheric asymmetry than is observed, and are $\sim 0.1 \mathrm{mBq} \mathrm{SCM}^{-1}$ lower than the observed values across the entire latitude range. An interhemispheric asymmetry is seen in the zonal mean values for all three simulations; the better agreement of the GMI/NCAR simulation sampled at the observation locations is thus due to regional effects.

Figure $9 \mathrm{~b}$ shows the $16-20 \mathrm{~km}$ region (roughly 100 $50 \mathrm{hPa}$ ). This region lies within the stratosphere at all latitudes. The observations reveal a broad tropical maximum of $\sim 0.3-0.35 \mathrm{mBq} \mathrm{SCM}{ }^{-1}$, with decreasing concentrations from the mid to higher latitudes in both hemispheres. As in Fig. 9a, the GMI/NCAR simulation agrees best with the observations, although the tropical maximum is $\sim 15 \%$ higher than observed and the falloff at higher latitudes appears
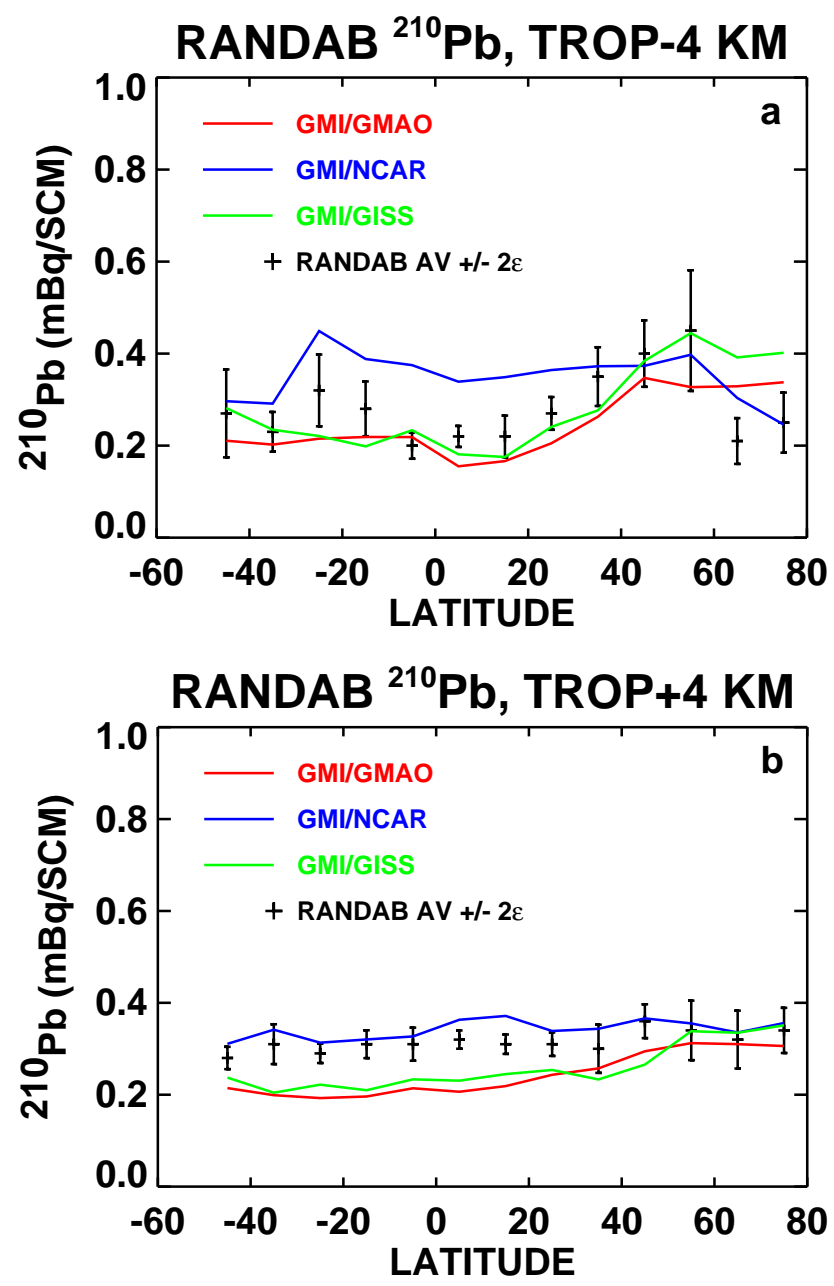

Fig. 10. Comparison of observed and simulated meridional distributions of ${ }^{210} \mathrm{~Pb}$ in the: (a) tropopause $-4 \mathrm{~km}$ region, and (b) tropopause $+4 \mathrm{~km}$ region. Observed distributions are calculated by averaging data from the US Environmental Measurement Laboratory RANDAB database into $10^{\circ}$ bins centered at $-45^{\circ},-35^{\circ}, \ldots$, $75^{\circ}$. Tropopause height estimates for the RANDAB data are not part of the climatology. These were determined by calculating the thermal tropopause height at the location and time of the observations using the NCEP 50-year reanalysis (Kistler et al., 2001). Error bars represent \pm 2 times the standard error of the averages. Simulated distributions are obtained by sampling model at observation locations and treating the sampled output in the same manner as the observations.

larger than seen in the observations. The GMI/GMAO and GMI/GISS distributions are basically flat, and do not exhibit the tropical maximum/high latitude falloff that characterizes the observations. Tropical values are $\sim 35 \%$ lower than observed. Both simulations show slightly more ${ }^{210} \mathrm{~Pb}$ at high northern latitudes relative to high southern latitudes.

The comparisons shown in Fig. 9 have been made without reference to the tropopause. Since the tropopause marks a boundary between two dynamically distinct regions, it is 

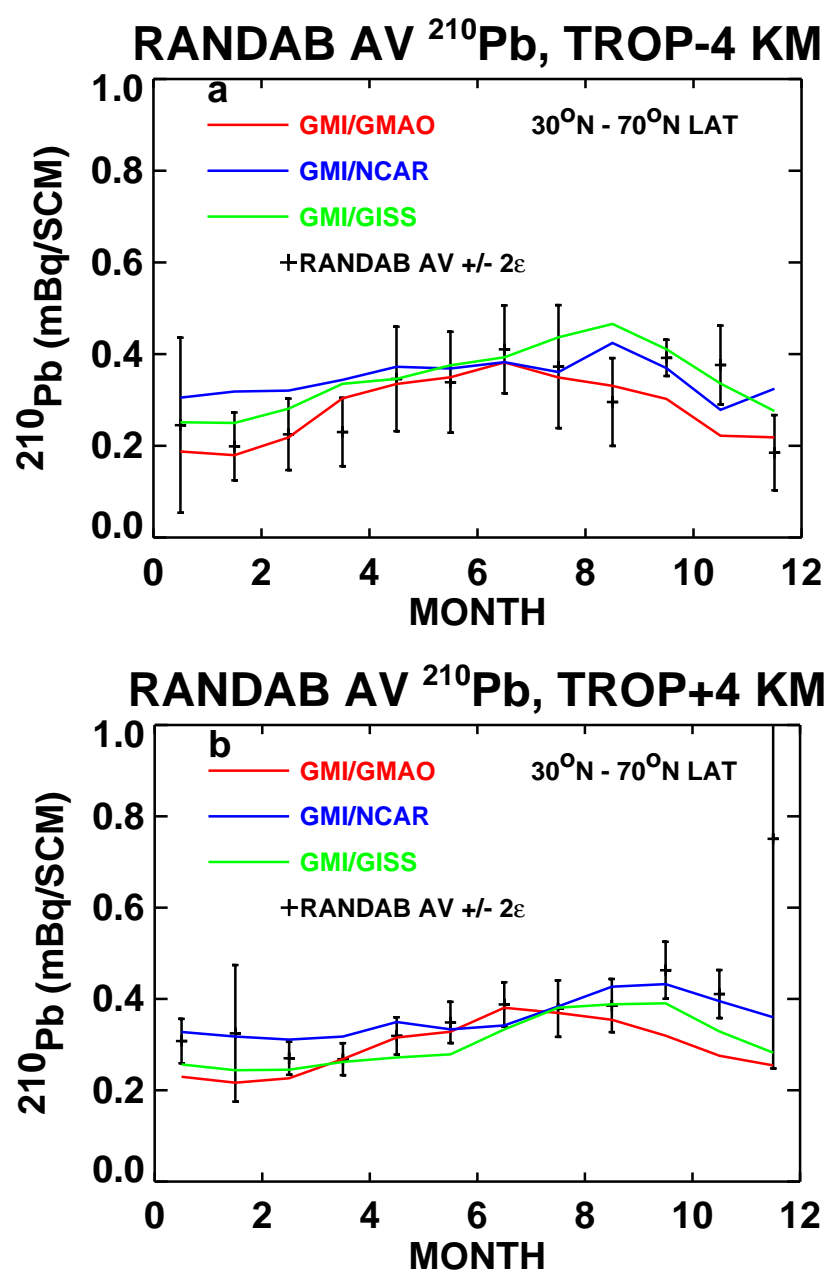

Fig. 11. Comparison of observed and simulated midlatitude average seasonal cycle of ${ }^{210} \mathrm{~Pb}$ in the: (a) tropopause $-4 \mathrm{~km}$ region, and (b) tropopause $+4 \mathrm{~km}$ region. Observed distributions are calculated by averaging data from the US Environmental Measurement Laboratory RANDAB database between $30^{\circ}-70^{\circ}$ by month. Tropopause height estimates are obtained as described in caption for Fig. 10. Simulated output is treated as described in caption for Fig. 10.

possible that some of the differences between the observations and simulations seen in Fig. 9 are due to differences in tropopause location. We therefore have constructed averages of observations lying between the tropopause and $4 \mathrm{~km}$ below the tropopause (Fig. 10a) and $4 \mathrm{~km}$ above the tropopause (Fig. 10b). Note that the tropopause height at the measurement locations is not part of the RANDAB database. In order to construct this figure we determined the tropopause altitude at each observation longitude, latitude, and time using the National Center for Environmental Prediction (NCEP) 50-year reanalysis product (Kistler et al., 2001).

In Fig. 10a, the observed distribution is similar to the structure seen in Fig. 9a, which shows ${ }^{210} \mathrm{~Pb}$ averaged over the $12-16 \mathrm{~km}$ region. The lowest values are in the tropics, with midlatitude peaks. Note however that the meridional gradient here characterizes the upper troposphere at all latitudes, and is not due to a transition from the tropical upper troposphere to the midlatitude lower stratosphere, as is the case for Fig. 9. All of the model simulations agree well with the RANDAB observations in the midlatitudes, particularly in the Northern Hemisphere. The GMI/GISS and GMI/GMAO simulations are systematically low through the tropics and subtropics, consistent with the $12-16 \mathrm{~km}$ average shown in Fig. 9a, but here the discrepancy between the model and the observations is not as large. In contrast, the high bias of the GMI/NCAR simulation relative to the observations is larger throughout the tropics and subtropics than seen in Fig. 9a. Note that the tropical and subtropical simulation averages have all moved to higher values in Fig. 10a relative to Fig. 9a. While this improves the agreement with observations for the GMI/GISS and GMI/GMAO simulations, it worsens the agreement for the GMI/NCAR simulation. The reason for the higher simulated values in Fig. 10a is that the average height of the points included in the $4 \mathrm{~km}$ region below the tropopause is $\sim 0.5-$ $1 \mathrm{~km}$ higher than the average height of the points included in the $12-16 \mathrm{~km}$ average. Fewer of the points in the relativeto-the-tropopause average lie in the tropical minimum region shown in Fig. 7, so the average values increase.

Figure $10 \mathrm{~b}$ compares the meridional distribution of RANDAB ${ }^{210} \mathrm{~Pb}$ measurements with the three model simulations in the $4 \mathrm{~km}$ region above the tropopause. All three model simulations agree well with the observations in the Northern hemisphere above $50^{\circ} \mathrm{N}$. At lower latitudes the GMI/GISS and GMI/GMAO simulations are 30\% low. The GMI/NCAR simulation agrees well with the RANDAB simulations over the entire latitude range sampled by the observations. This better agreement with observations in the lower stratosphere of the GMI/NCAR simulation relative to the other two simulations is consistent with Fig. 9b.

So far we have only compared annually averaged RANDAB data with the GMI model simulations. The RANDAB data is sufficiently spread throughout the year to reveal seasonal variations as well. Figure 11a compares the seasonal cycle of monthly averaged ${ }^{210} \mathrm{~Pb}$ in the upper troposphere ( $4 \mathrm{~km}$ below tropopause to tropopause) from RANDAB in the Northern Hemisphere mid to high latitudes $\left(30^{\circ} \mathrm{N}-70^{\circ} \mathrm{N}\right)$ with output from the three GMI simulations. The observations indicate a wintertime minimum in the concentration of ${ }^{210} \mathrm{~Pb}$ of $\sim 0.2 \mathrm{mBq} \mathrm{SCM}^{-1}$ and a broad summer/fall maximum of $\sim 0.35-0.4 \mathrm{mBq} \mathrm{SCM}^{-1}$. The GMI/GMAO and GMI/GISS simulations reproduce the observed seasonal cycle reasonably well. The GMI/NCAR simulation shows a weak seasonal cycle, and overestimates wintertime ${ }^{210} \mathrm{~Pb}$ by $\sim 50 \%$. The existence of a summertime peak in upper tropospheric, midlatitude ${ }^{210} \mathrm{~Pb}$ concentrations and a wintertime minimum is consistent with the fact that continental convective transport peaks in the summer (Liu et al., 1984). This increases the convective transport of ${ }^{222} \mathrm{Rn}$ (as can be seen by comparing the July average Northern 
Hemisphere upper tropospheric ${ }^{222} \mathrm{Rn}$ concentrations shown in Fig. 4 with the annual average values shown in Fig. 3), and consequently the amount of upper tropospheric ${ }^{210} \mathrm{~Pb}$ during the summer.

Figure $11 \mathrm{~b}$ compares the seasonal cycle of monthly averaged ${ }^{210} \mathrm{~Pb}$ in the lower stratosphere (tropopause to $4 \mathrm{~km}$ above the tropopause) from RANDAB to the GMI simulations, similarly to Fig. 11a. The RANDAB observations indicate a peak that is now shifted into the Fall (OctoberDecember) and a minimum value that is shifted into the Spring (March/April) time period. This is reasonable considering that the Northern Hemisphere fall is the time of year when adiabatic (isentropic) troposphere-to-stratosphere transport into the mid and high latitudes peaks and net extratropical stratosphere-to-troposphere exchange (diabatic plus adiabatic) is a minimum (Schoeberl, 2004). At this time, ${ }^{210} \mathrm{~Pb}$ transported into the extratropical lower stratosphere just above the tropopause, either directly or as ${ }^{222} \mathrm{Rn}$ which subsequently decays, can build up. During the spring, when isentropic troposphere-to-stratospheric transport is a minimum and net stratosphere-to-troposphere exchange is at its maximum, ${ }^{210} \mathrm{~Pb}$ will be flushed from the stratosphere and so its concentration will reach a minimum value.

The three GMI simulations show some shifting of the timing of peak values to later in the year, compared to Fig. 11a. The GMI/NCAR simulation appears to match the observations best in this region, though its springtime minimum is high compared to the observations and the difference between the plots shown in Fig. 11a (below the tropopause) and Fig. 11b (above the tropopause) is subtle. Overall, the model simulations appear to capture the extratropical Northern Hemisphere seasonal cycle in the upper troposphere and lower stratosphere reasonably well.

\subsection{Effects of convective processes}

Vertical transport in a model simulation above the PBL is governed by resolved vertical winds and the model's parameterization of sub grid-scale convective processes (vertical diffusive transport above the PBL is negligible with these three meteorlogical data sets). Since both the resolved vertical winds and the convective data (vertical mass fluxes, entrainment and detrainment rates) used in the GMI CTM are taken from the meteorological data sets used to drive the model, it is interesting to evaluate the relative importance of convective processes in the three GMI simulations for both ${ }^{222} \mathrm{Rn}$ and ${ }^{210} \mathrm{~Pb}$. For this purpose we reran the three simulations without invoking the convective transport operator, keeping all other simulation elements the same (Note that without convective transport, there will also be no scavenging in convective updrafts). We evaluate the role of convective processes by comparing the two simulations.

Figure 12 shows the percentage of annuallyaveraged, zonal mean ${ }^{222} \mathrm{Rn}$ that results from convective processes in each simulation, as expressed by:
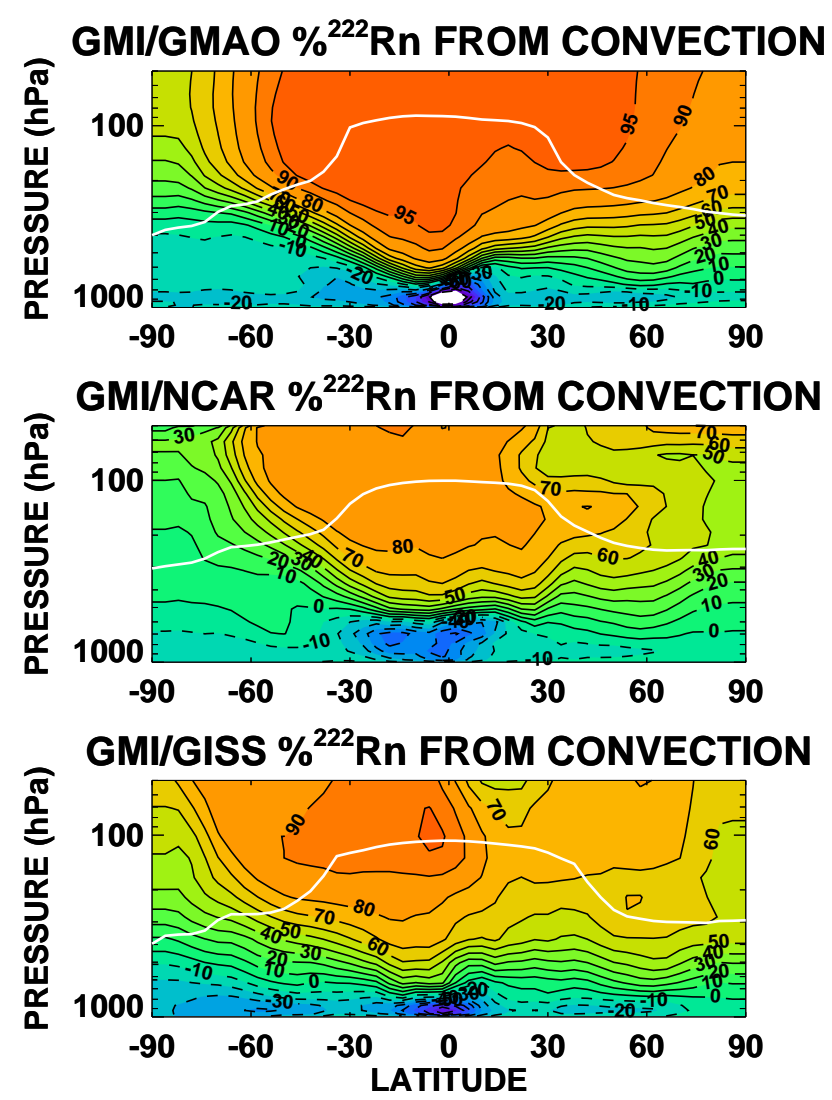

Fig. 12. Percentage of zonal mean, annually averaged ${ }^{222} \mathrm{Rn}$ which is due to convective transport in the GMI/GMAO simulation (top panel), GMI/NCAR simulation (middle panel), and GMI/GISS simulation (bottom panel). Values are calculated as $\left({ }^{222} \mathrm{Rn}_{\text {conv }}-{ }^{222} \mathrm{Rn}_{\text {no conv }}\right){ }^{222} \mathrm{Rn}_{\text {conv }}$, where the subscripts refer to simulations made with and without calling the convective transport and scavenging operator.

$100\left({ }^{222} \mathrm{Rn}_{\text {conv }}-{ }^{222} \mathrm{Rn}_{\text {no conv }}\right){ }^{222} \mathrm{Rn}_{\text {conv }}$. Where values are negative, the ${ }^{222} \mathrm{Rn}$ concentrations in the no convection simulation exceed that of the case with convective processes, meaning that convective processing is acting to reduce ${ }^{222} \mathrm{Rn}$. In all three simulations, the convective parameterization has the expected effect of reducing ${ }^{222} \mathrm{Rn}$ near the surface and increasing it at higher altitudes. The largest decreases occur near the surface at the equator, and the fraction of convectively transported ${ }^{222} \mathrm{Rn}$ increases with altitude. This is understandable because convective transport time scales are shorter than those which characterize large scale vertical transport. Non-convectively transported ${ }^{222} \mathrm{Rn}$ will decay into ${ }^{210} \mathrm{~Pb}$ before reaching the higher altitudes, so the fraction of ${ }^{222} \mathrm{Rn}$ due to convective transport should increase with altitude. In all three simulations the largest tropospheric convectively transported fractions are in the tropical mid to upper troposphere. The GMI/GMAO simulation has the largest fractions of over 95\% throughout much of the tropical upper troposphere extending into the stratosphere. 

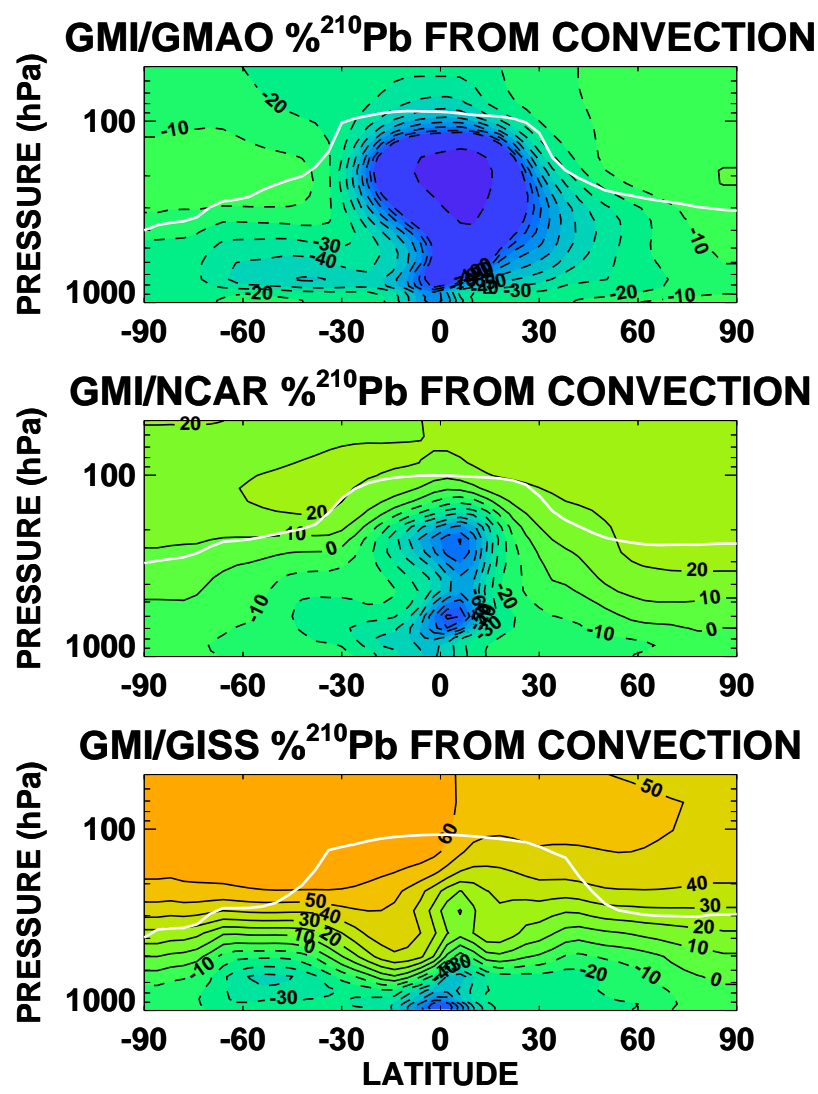

Fig. 13. Percentage of zonal mean, annually averaged ${ }^{210} \mathrm{~Pb}$ which is due to convective transport and scavenging in the GMI/GMAO simulation (top panel), GMI/NCAR simulation (middle panel), and GMI/GISS simulation (bottom panel). Values are calculated as described in caption for Fig. 12.

The GMI/NCAR tropical upper troposphere has values of $\sim 80 \%$, and the GMI/GISS simulation has values ranging upwards from $60 \%$. Note that the differences between the simulations are due both to variations in convective transport (convective mass fluxes and the amount of mass detrained and entrained at each level), and in the strength of large scale vertical transport in each simulation. Figure 12 indicates that in all three simulations, convective transport is responsible for transporting more ${ }^{222} \mathrm{Rn}$ into the upper troposphere and lower stratosphere than large-scale vertical transport. However, in the GMI/NCAR and GMI/GISS simulations large scale transport plays more of a role than in the GMI/GMAO simulation. It should be noted that Fig. 12 indicates only the relative importance of convective transport. In absolute terms convection in the GMI/NCAR simulations transports the largest amount of ${ }^{222} \mathrm{Rn}$.

Figure 13 shows the convectively processed ${ }^{210} \mathrm{~Pb}$ percentages for each of the simulations, calculated in the same manner as for ${ }^{222} \mathrm{Rn}$. In this case, the differences between the simulations are more striking than for ${ }^{222} \mathrm{Rn}$. In the GMI/GMAO simulation, values are negative throughout the

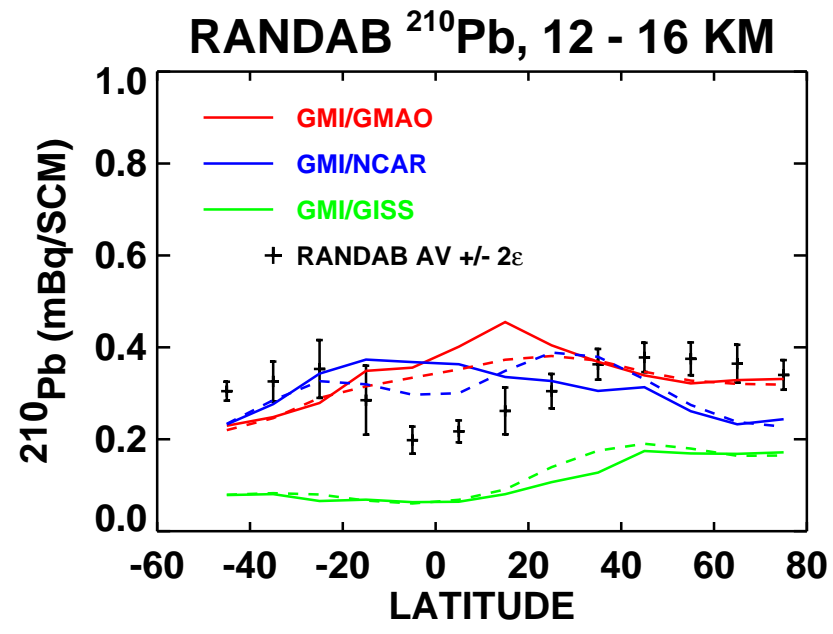

Fig. 14. Same as Fig. 9a, except that the model meridional distributions are from simulations in which the convective transport and scavenging operator was not called.

troposphere and lower stratosphere, meaning that without convective processing, ${ }^{210} \mathrm{~Pb}$ would be higher everywhere. Although convection moves ${ }^{222} \mathrm{Rn}$ above the lower troposphere and hence substantially increases the ${ }^{210} \mathrm{~Pb}$ source term at altitudes above the lower troposphere, in this simulation that source does not completely compensate for the amount of convective scavenging of ${ }^{210} \mathrm{~Pb}$. In contrast, at higher altitudes in the GMI/NCAR and GMI/GISS simulations, convective processes contribute ${ }^{210} \mathrm{~Pb}$. In the GMI/NCAR simulation, convection is responsible for up to about $20 \%$ of the ${ }^{210} \mathrm{~Pb}$ concentrations in the Northern Hemisphere upper troposphere/lower stratosphere. In the GMI/GISS simulation, concentrations are increased starting at lower altitudes than in the GMI/NCAR case, and convection contributes as much as $60 \%$ of the ${ }^{210} \mathrm{~Pb}$ at the tropopause in the Southern Hemisphere subtropics and low middle latitudes.

Previous publications have demonstrated the importance of convective transport to improve model representation of vertical profiles of ${ }^{222} \mathrm{Rn}$ (e.g., Jacob and Prather, 1990). It is interesting to see how the presence of convective transport affects the agreement of the three GMI simulations with upper tropospheric/lower stratospheric ${ }^{210} \mathrm{~Pb}$ observations. Figure 14 shows the meridional distribution of ${ }^{210} \mathrm{~Pb}$ in the 12 $16 \mathrm{~km}$ tropical upper troposphere/lower stratosphere region from simulations without convective transport compared to RANDAB observations. The corresponding comparison including convection is shown in Fig. 9a. Without convection the three simulations are in substantially worse agreement with the RANDAB observations, particularly in the tropics. Here observations and simulations including convection are at a relative minimum compared to midlatitudes; without convection, both the GMI/GMAO and GMI/NCAR simulations peak in the tropics. In the GMI/GISS simulation 
without convection, ${ }^{210} \mathrm{~Pb}$ concentrations are smaller everywhere, particularly in the Southern Hemisphere midlatitudes. Overall, Fig. 14 demonstrates the importance of both convective transport and convective scavenging in reproducing observed meridional distributions of ${ }^{210} \mathrm{~Pb}$ in the upper troposphere/lower stratosphere region.

Figures 12 and 13 suggest that there are substantial differences between the three GMI simulations in the mechanisms and thus the rates of vertical transport from the surface into the lower stratosphere. Apparently, surface emissions in the GMI/GMAO simulation will be transported from the surface into the upper troposphere/lower stratosphere more rapidly than occurs in either of the other two simulations. One way of testing this is to determine the fraction of the ${ }^{210} \mathrm{~Pb}$ in the stratosphere resulting from the decay of ${ }^{222} \mathrm{Rn}$ that was already in the stratosphere at the time of its decay. This pathway, where a source gas such as ${ }^{222} \mathrm{Rn}$ enters the stratosphere prior to its conversion to a product gas like ${ }^{210} \mathrm{~Pb}$, is generally referred to as Source Gas Injection (SGI). The alternative transport pathway, where the source species decays into the product species in the troposphere prior to its transport into the stratosphere, is known as Product Gas Injection (PGI) (WMO, 2003).

Figure 15 shows the percentage of stratospheric ${ }^{210} \mathrm{~Pb}$ that is due to the SGI pathway for the three model simulations. The GMI/GMAO simulation is characterized by relatively large percentages of between $15 \%$ in the Southern Hemisphere to over $30 \%$ at high northern latitudes in the lower stratosphere. The GMI/NCAR simulation lies at the other end of the spectrum, with only $\sim 3-5 \%$ of its stratospheric ${ }^{210} \mathrm{~Pb}$ burden due to SGI. The GMI/GISS simulation lies between the other two, with $\sim 5-15 \%$ of its stratospheric ${ }^{210} \mathrm{~Pb}$ due to SGI. Thus, as the importance of convective vertical transport relative to large scale vertical transport increases, so does the importance of the SGI pathway relative to PGI in these three simulations.

\section{Summary and conclusions}

We have used the Global Modeling Initiative CTM to simulate the radionuclides ${ }^{222} \mathrm{Rn}$ and ${ }^{210} \mathrm{~Pb}$ using three different meteorological data sets. Our goal was to examine how well each of the simulations compared with observations, and to gauge the amount of variability between the simulations due to the different meteorological data.

All three simulations produce morphologically similar annually averaged zonal mean ${ }^{222} \mathrm{Rn}$ and ${ }^{210} \mathrm{~Pb}$ distributions. The simulations qualitatively reproduce a number of important features seen in observations of ${ }^{222} \mathrm{Rn}$ and ${ }^{210} \mathrm{~Pb}$ including the meridional structure of ${ }^{210} \mathrm{~Pb}$ deposition fluxes, the summertime continental ${ }^{222} \mathrm{Rn}$ profile, the meridional distribution of annually averaged surface ${ }^{210} \mathrm{~Pb}$ concentrations, and the meridional distribution of annually averaged ${ }^{210} \mathrm{~Pb}$ in

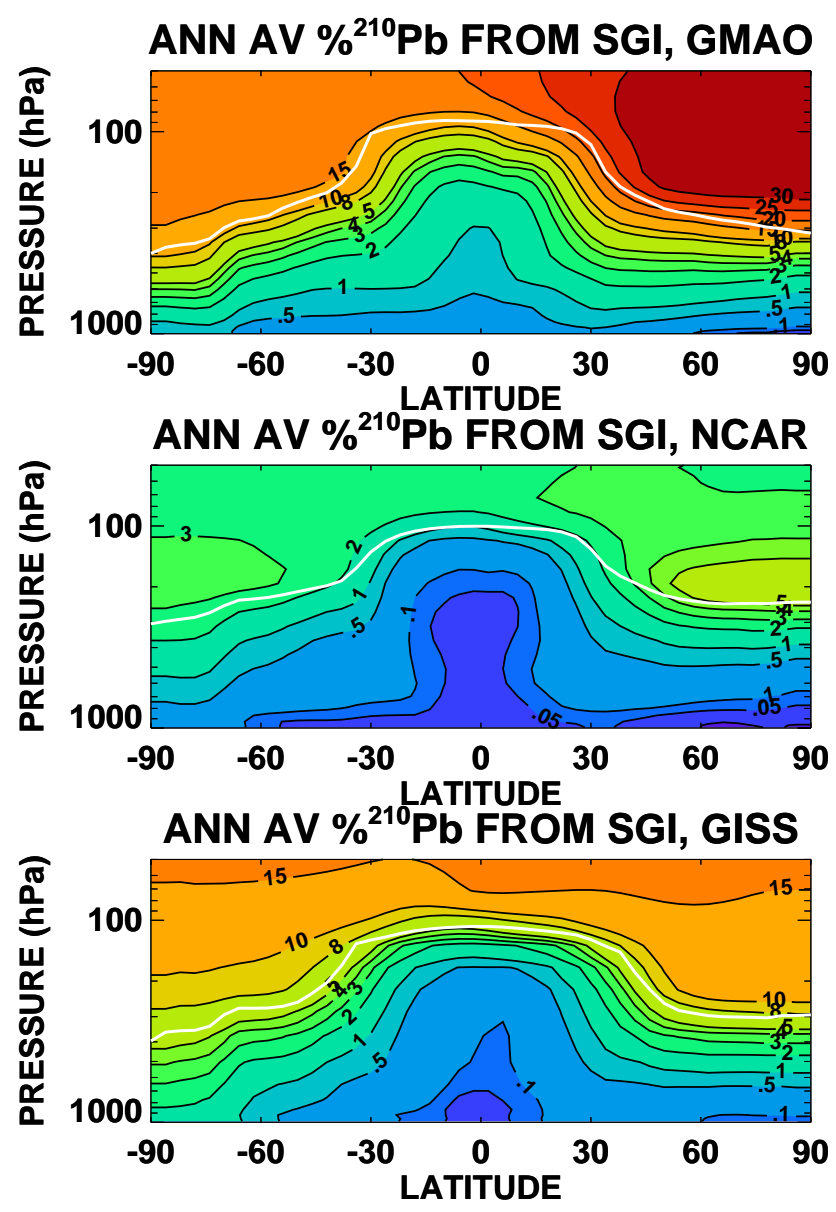

Fig. 15. Percentage of annually averaged, zonal mean ${ }^{210} \mathrm{~Pb}$ which results from the decay of ${ }^{222} \mathrm{Rn}$ that is in the stratosphere at the time of its decay. Top panel: GMI/GMAO simulation. Middle panel: GMI/NCAR simulation. Bottom panel: GMI/GISS.

the upper troposphere and lower stratosphere from the tropics to mid/high latitudes.

The simulations also display some common discrepancies in comparison with observations. Midlatitude summertime ${ }^{222} \mathrm{Rn}$ profiles underestimate mid-tropospheric ${ }^{222} \mathrm{Rn}$, perhaps because convective transport in all three simulations moves ${ }^{222} \mathrm{Rn}$ to too high altitudes before detraining. Southern Hemisphere high latitude surface ${ }^{210} \mathrm{~Pb}$ is lower than observed in all three simulations. Northern Hemisphere midlatitude surface ${ }^{210} \mathrm{~Pb}$ is $15-20 \%$ lower than observed. The fact that ${ }^{210} \mathrm{~Pb}$ deposition is in good agreement with observations in the Northern Hemisphere midlatitudes suggests that the cloud scavenging frequency in the Northern Hemisphere midlatitudes may be too high. Last, annually averaged surface ${ }^{210} \mathrm{~Pb}$ concentrations tend to be higher than observed at South American locations.

No one simulation consistently outperforms the other two in terms of its agreement with observations. In fact, if the performance of the simulations in each of the 10 comparisons 
with observations presented in this paper is ranked and equally weighted, the three simulations receive equivalent scores. However, if just the upper tropospheric/lower stratospheric comparisons with observations are considered, then the GMI/NCAR simulation outperforms the other two.

A unique feature of this study is the use of the RANDAB database of upper atmosphere radionuclide observations compiled by the DOE (now DHS) Environmental Measurement Laboratory. The lack of a good source of ${ }^{210} \mathrm{~Pb}$ observations in the upper troposphere/lower stratosphere was identified as a limiting factor in the use of ${ }^{210} \mathrm{~Pb}$ for model intercomparisons by Rasch et al. (2000). This paper demonstrates the utility of this database, which is currently available on the Internet, and contains measurements of numerous radionuclides including ${ }^{7} \mathrm{Be}$ and ${ }^{90} \mathrm{Sr}$. The potential of this database to inform modeling of the global atmosphere has not been exhausted by this study.

Despite the apparent similarities, the vertical transport mechanisms in the simulations differ substantially. Specifically, convective transport plays a more important role in the GMI/GMAO simulation relative to large scale vertical transport than is seen in either of the other two simulations. The evidence for this dominance is a larger fraction of upper tropospheric and lower stratospheric tropical ${ }^{222} \mathrm{Rn}$ resulting from convective processes in the GMI/GMAO simulation than occurs in the other two simulations, and a larger fraction of stratospheric ${ }^{210} \mathrm{~Pb}$ resulting from the source gas injection (SGI) transport pathway as opposed to product gas injection (PGI). It is important to note however that these facts do not imply direct injection of ${ }^{222} \mathrm{Rn}$ into the stratosphere in convective updrafts, just that more of the stratospheric ${ }^{222} \mathrm{Rn}$ in the GMI/GMAO simulation was transported convectively during some part of its trip from the surface to the stratosphere. It is also important to note that in all three simulations convective processes are the dominant mechanism for ${ }^{222} \mathrm{Rn}$ transport above the mid troposphere, and that the removal of convective transport and scavenging degrades the agreement with observations in all three simulations.

Acknowledgements. The authors would like to thank R. Leifer, recently retired from the DOE (now DHS) EML, for providing the RANDAB database and comments concerning its appropriate use, B. Das of the GMI core modeling team for running the model simulations, and the GMI Science Team for useful comments on paper content and structure. Funding for this work was provided by the NASA Modeling, Analysis, and Prediction Program. Participation of the Lawrence Livermore National Laboratory author occurred through the University of California under the auspices of the US Department of Energy contract W-7405-ENG-48.

Edited by: M. G. Lawrence

\section{References}

Allen, D. J., Rood, R. B., Thompson, A. M., and Hudson, R. D.: Three-dimensional radon 222 calculations using assimilated meteorological data and a convective mixing algorithm, J. Geophys. Res., 101(D3), 6871-6881, 1996.

Balkanski, Y. J., Jacob, D. J., Arimoto, R., and Kritz, M. A.: Distribution of Rn-222 over the North Pacific - Implications for continental influences, J. Atmos. Chem., 14(1-4), 353-374, 1992.

Balkanski, Y. J., Jacob, D. J., Gardner, G. M., Graustein, W. C., and Turekian, K. K.: Transport and residence times of tropospheric aerosols inferred from a global 3-dimensional simulation of $\mathrm{Pb}$ 210, J. Geophys. Res., 98(D11), 20 573-20 586, 1993.

Brost, R. A., Feichter, J., and Heimann, M.: 3-Dimensional simulation of Be-7 in a global climate model, J. Geophys. Res., 96(D12), 22 423-22 445, 1991.

Considine, D. B., Connell, P. S., Bergmann, D., Rotman, D. A., and Strahan, S. E.: Sensitivity of global modeling initiative model predictions of Antarctic ozone recovery to input meteorological fields, J. Geophys. Res., 109(D15), D15301, doi:10.1029/2003JD004487, 2004a.

Considine, D. B., Connell, P. S., and Logan, J. A.: Simulating ozone in the near tropopause region with a new combined model of the stratosphere and troposphere, in: Quadrennial Ozone Symposium QOS 2004, edited by: Zerefos, C., pp. 739-740, International Ozone Commission, Kos, Greece, 2004b.

Considine, D. B., Douglass, A. R., Connell, P. S., Kinnison, D. E., and Rotman, D. A.: A polar stratospheric cloud parameterization for the global modeling initiative three-dimensional model and its response to stratospheric aircraft, J. Geophys. Res., 105(D3), 3955-3973, 2000.

DelGenio, A. D. and Yao, M-S: Efficient cumulus parameterization for long-term climate studies: The GISS scheme, in: Cumulus Parameterization, AMS Monogr. Ser., edited by: Emanuel, K. and Raymond, D., Am. Meteorol. Soc., Boston, Mass., 1992.

Dentener, F., Feichter, J., and Jeuken, A.: Simulation of the transport of $\mathrm{Rn}^{222}$ using on-line and off-line global models at different horizontal resolutions: a detailed comparison with measurements, Tellus, 51B, 573-602, 1999.

Douglass, A. R., Stolarski, R. S., Strahan, S. E., and Connell, P. S.: Radicals and reservoirs in the GMI chemistry and transport model: Comparison to measurements, J. Geophys. Res., 109(D16302), doi:10.1029/2004JD004632, 2004.

Feichter, J., Brost, R. A., and Heimann, M.: 3-Dimensional Modeling of the concentration and deposition of Pb-210 Aerosols, J. Geophys. Res., 96(D12), 22 447-22 460, 1991.

Gayet, J. F., Asano, S., Yamazaki, A., Uchiyama, A., Sinyuk, A., Jourdan, O., and Auriol, F.: Two case studies of winter continental-type water and mixed-phase stratocumuli over the sea -1 . Microphysical and optical properties, J. Geophys. Res., 107(D21), 4569, doi:10.1029/2001JD001106, 2002.

Giorgi, F. and Chameides, W. L.: Rainout lifetimes of highly soluble aerosols and gases as inferred from simulations with a general circulation model, J. Geophys. Res., 91(D13), 14 367-14376, 1986.

Gong, S. L., Barrie, L. A., and Blanchet, J. P.: Modeling sea-salt aerosols in the atmosphere, 1. Model development, J. Geophys. Res., 102(D3), 3805-3818, 1997.

Guelle, W., Balkanski, Y. J., Dibb, J. E., Schulz, M., and Dulac, F.: Wet deposition in a global size-dependent aerosol transport 
model 2. Influence of the scavenging scheme on $\mathrm{Pb}-210$ vertical profiles, surface concentrations, and deposition, J. Geophys. Res., 103(D22), 28 875-28 891, 1998.

Gupta, M. L., Douglass, A. R., Kawa S. R., and Pawson, S.: Use of radon for evaluation of atmospheric transport models: sensitivity to emissions, Tellus, 56B, 404-412, 2004.

Jacob, D. J., Fan, S. M., Wofsy, S. C., et al.: Deposition of ozone to tundra, J. Geophys. Res., 97(D15), 16473-16479, 1992.

Jacob, D. J. and Prather, M. J.: Radon-222 as a test of convective transport in a general circulation model, Tellus, 42B, 118-134, 1990.

Jacob, D. J., Prather, M. J., Rasch, P. J., et al.: Evaluation and intercomparison of global atmospheric transport models using Rn-222 and other short-lived tracers, J. Geophys. Res., 102(D5), 5953-5970, 1997.

Jacob, D. J. and Wofsy, S. C.: Budgets of reactive nitrogen, hydrocarbons, and ozone over the Amazon forest during the wet season, J. Geophys. Res., 95(D10), 16737-16 754, 1990.

Kiehl, J. T., Hack, J. J., Bonan, G. B., Boville, B. A., Williamson, D. L., and Rasch, P. J.: The National Center for Atmospheric Research Community Climate Model: CCM3, J. Clim., 11(6), 1131-1149, 1998.

Kinnison, D. E., Connell, P. S., Rodriguez, J. M., et al.: The Global Modeling Initiative assessment model: Application to highspeed civil transport perturbation, J. Geophys. Res., 106(D2), 1693-1711, 2001.

Kistler, R., Kalnay, E., Collins, W., et al.: The NCEP-NCAR 50year reanalysis: Monthly means CD-ROM and documentation, Bull. Amer. Meteorol. Soc., 82(2), 247-267, 2001.

Koch, D. and Rind, D.: Beryllium 10 beryllium 7 as a tracer of stratospheric transport, J. Geophys. Res., 103(D4), 3907-3917, 1998.

Kritz, M. A., Rosner, S. W., and Stockwell, D. Z.: Validation of an off-line three-dimensional chemical transport model using observed radon profiles - 1. Observations, J. Geophys. Res., 103(D7), 8425-8432, 1998.

Lambert, G., Polian, G., Sanak, J., Ardouin, B., Buisson, A., Jegou, A., and Le Roulley, J. C.: Cycle du radon et de ses descendants: Application a l'etude des echanges tropospherestratosphere, Ann. Geophys., 48, 497-531, 1982.

Lee, H. N. and Feichter, J.: An Intercomparison of wet precipitation scavenging schemes and the emission rates of Rn-222 for the simulation of global transport and deposition of $\mathrm{Pb}-210$, J. Geophys. Res., 100(D11), 23 253-23 270, 1995.

Lee, H. N., Wan, G., Zheng, X., Sanderson, C. G., Josse, B., Wang, S., Yang, W., Tang, J., and Wang, C.: Measurements of ${ }^{210} \mathrm{~Pb}$ and ${ }^{7} \mathrm{Be}$ in China and their analysis accompanied with global model calculations of ${ }^{210} \mathrm{~Pb}$, J. Geophys. Res., 109(D22203), doi:10.1029/2004JD005061, 2004.

Lin, S. J. and Rood, R. B.: Multidimensional flux-form semiLagrangian transport schemes, Mon. Weather Rev., 124(9), 2046-2070, 1996.

Liu, H., Jacob, D. J., Bey, I., and Yantosca, R. M.: Constraints from $\mathrm{Pb}-210$ and $\mathrm{Be}-7$ on wet deposition and transport in a global three-dimensional chemical tracer model driven by assimilated meteorological fields, J. Geophys. Res., 106(D11), 12 109_ $12128,2001$.

Liu, S. C., McAfee, J. A., and Cicerone, R. J.: Rn-222 and tropospheric vertical transport, J. Geophys. Res., 89(ND5), 7291-
7297, 1984.

Mahowald, N. M., Rasch, P. J., Eaton, B. E., Whittlestone, S., and Prinn, R. G.: Transport of (222)radon to the remote troposphere using the model of atmospheric transport and chemistry and assimilated winds from ECMWF and the National Center for Environmental Prediction NCAR, J. Geophys. Res., 102(D23), 28 139-28 151, 1997.

Moorthi, S. and Suarez, M. J.: Relaxed Arakawa-Schubert - A parameterization of moist convection for general circulation models, Mon. Wea. Rev., 120(6), 978-1002, 1992.

Nicholls, S. and Leighton, J.: An observational study of the structure of stratiform cloud sheets, 1. Structure, Quart. J. Royal Met. Soc., 112(472), 431-460, 1986.

Preiss, N., Melieres, M. A., and Pourchet, M.: A compilation of data on lead 210 concentration in surface air and fluxes at the air-surface and water-sediment interfaces, J. Geophys. Res., 101(D22), 28 847-28 862, 1996.

Rasch, P. J., Feichter, J., Law, K., et al.: A comparison of scavenging and deposition processes in global models: results from the WCRP Cambridge Workshop of 1995, Tellus B, 52(4), 10251056, 2000.

Rehfeld, S. and Heimann, M.: Three dimensional atmospheric transport simulation of the radioactive tracers $\mathrm{Pb}-210, \mathrm{Be}-7, \mathrm{Be}-$ 10, and Sr-90, J. Geophys. Res., 100(D12), 26 141-26 161, 1995.

Rodriguez, J. M., Logan, J. A., Bergmann, D., Megretskaia, I., Jacob, D. J., Xie, H., Das, B., and Strahan, S. E.: The Impact of meteorological fields on tropospheric ozone distributions calculated by the Global Modeling Initiative (GMI) chemicaltransport model, in: Quadrennial Ozone Symposium QOS 2004, edited by: Zerefos, C., pp. 147, International Ozone Commission, Kos, Greece, 2004.

Rotman, D. A., Tannahill, J. R., Kinnison, D. E., et al.: Global Modeling Initiative assessment model: Model description, integration, and testing of the transport shell, J. Geophys. Res., 106(D2), 1669-1691, 2001.

Sanak, J., Gaudry, A., and Lambert, G.: Size distribution of Pb-210 aerosols over oceans, Geophys. Res. Lett., 8(10), 1067-1069, 1981.

Schoeberl, M. R.: Extratropical stratosphere-troposphere mass exchange, J. Geophys. Res., 109(D13), D13303, doi:10.1029/2004JD004525, 2004.

Schoeberl, M. R., Douglass, A. R., Zhu, Z. X., and Pawson, S.: A comparison of the lower stratospheric age spectra derived from a general circulation model and two data assimilation systems, J. Geophys. Res., 108(D3), 4113, doi:10.1029/2002JD002652, 2003.

Seinfeld, J. H. and Pandis, S. N.: Atmospheric Chemistry and Physics, 1326 pp., John Wiley \& Sons, Inc., New York, 1998.

Stockwell, D. Z., Kritz, M. A., Chipperfield, M. P., and Pyle, J. A.: Validation of an off-line three-dimensional chemical transport model using observed radon profiles -2 . Model results, J. Geophys. Res., 103(D7), 8433-8445, 1998.

Strahan, S. E. and Douglass, A. R.: Evaluating the credibility of transport processes in simulations of ozone recovery using the Global Modeling Initiative three-dimensional model, J. Geophys. Res., 109(D05110), doi:10.1029/2003JD004238, 2004.

Turekian, K. K., Nozaki, Y., and Benninger, L. K.: Geochemistry of atmospheric radon and radon products, Ann. Rev. Earth Plan. Sci., 5, 227-255, 1977. 
Wang, Y. H., Jacob, D. J., and Logan, J. A.: Global simulation of tropospheric O3-NOx-hydrocarbon chemistry 1. Model formulation, J. Geophys. Res., 103(D9), 10713-10725, 1998.

Wesely, M. L.: Parameterization of Surface Resistances to Gaseous Dry Deposition in Regional-Scale Numerical-Models, Atmos. Environ., 23(6), 1293-1304, 1989.

Wesely, M. L., Cook, D. R., Hart, R. L., and Speer, R. E.: Measurements and parameterization of particulate sulfur dry deposition over grass, J. Geophys. Res., 90(ND1), 2131-2143, 1985.
WMO (World Meteorological Organization): Scientific assessment of ozone depletion: 2002, Global Ozone Research and Monitoring Project - Report No. 47, 498 p., Geneva, 2003.

Zhang, G. J. and McFarlane, N. A.: Sensitivity of climate simulations to the parameterization of cumulus convection in the Canadian Climate Center general circulation model, Atmos. Ocean, 33(3), 407-446, 1995. 